\title{
Management of Bureaucrats and Public Service Delivery: Evidence from the Nigerian Civil Service*
}

\author{
Imran Rasul Daniel Rogger
}

June 2015

\begin{abstract}
We study how the management practices bureaucrats operate under relate to the quantity and quality of public services delivered. We do so exploiting data from the Nigerian Civil Service. For 4700 public sector projects, we have hand-coded independent engineering assessments of project completion rates and delivered quality. We supplement this with a survey eliciting management practices for bureaucrats in the 63 civil service organizations responsible for these projects, building on Bloom and Van Reenen [2007]. Management practices matter: a one standard deviation increase in bureaucrat's autonomy significantly increases project completion rates by $18 \%$; a one standard deviation increase in practices related to incentives/monitoring of bureaucrats significantly lowers project completion rates by $14 \%$. We show the negative impacts of incentive provision/monitoring arise because bureaucrats multi-task and incentives are poorly targeted, and because these management practices capture elements of subjective performance evaluation that leave scope for dysfunctional responses from bureaucrats. To support a causal interpretation of our findings, we document the determinants of management practices and examine channels through which organizations might endogenously adjust management practices. Our results provide novel insights into how changes in how bureaucrats are managed can have potentially large impacts on public service delivery in a developing country context. JEL Classification: J33, J38, O20.
\end{abstract}

${ }^{*}$ We gratefully acknowledge financial support from the Federal Government of Nigeria; the International Growth Centre [RA-2009-11-018], the Economic and Social Research Council [ES/G017352/1], the Institute for Fiscal Studies, and the Royal Economic Society. We thank the Presidency and the Office of the Head of the Civil Service of Nigeria for their support. We are grateful to the many government officials who have assisted us during this project but are too numerous to name individually, Daron Acemoglu, Nava Ashraf, Orazio Attanasio, Oriana Bandiera, Marianne Bertrand, Tim Besley, Nick Bloom, Richard Blundell, Tom Crossley, Jishnu Das, Esther Duflo, Christian Dustmann, Ben Faber, Andrew Foster, Lucie Gadenne, Luis Garicano, Robert Gibbons, Rachel Griffith, Stephen Hansen, Larry Katz, Henrik Kleven, Guy Laroque, Ed Lazear, Willy McCourt, Magne Mogstad, Paul Niehaus, Jonathan Phillips, Andrea Prat, Carol Propper, Juan Pablo Rud, Raffaella Sadun, John Van Reenen, Marcos Vera-Hernandez, Martin Williams and numerous seminar participants. All errors remain our own.

${ }^{\dagger}$ Rasul: UCL and IFS [i.rasul@ucl.ac.uk]; Rogger: World Bank Research Department [ drogger@worldbank.org]. 


\section{Introduction}

We study the correlates of effective public service delivery in a developing country context: Nigeria. To do so, we combine novel data sources linking the outputs of government bureaucracies with our own survey data eliciting a range of management practices that bureaucrats are subject to.

The effective functioning of the government bureaucracy matters: it is an important determinant of poverty, inequality, and economic growth as stressed by the emergent literature on state capacity [Acemoglu 2005, Besley and Persson 2010]. Effective public service delivery also matters from a microeconomic perspective: program evaluations of small-scale interventions often assume successful interventions can be effectively scaled-up by government.

However, despite the importance of government effectiveness for citizen welfare, economic analyses of incentives in the public sector have largely focused on the selection and motivation of politicians [Besley 2004, Gagliarducci and Nannicini 2013, Martinez-Bravo 2014], or on the response to incentives of frontline staff such as teachers and health workers [Muralidharan and Sundararaman 2011, Duflo et al. 2012, Ashraf et al. 2014]. In both rich and poor country contexts, there is little evidence linking the managerial practices the vital middle-tier of bureaucrats operate under, to public service delivery. Similarly, the public administration literature is almost devoid of concrete evidence linking practices in civil service organizations to public goods outcomes [Goldfinch et al. 2012]. It is this knowledge gap that we start to fill.

Banerjee et al. [2007] emphasize two constraints restricting research on public service delivery in developing countries: (i) the process of project implementation is rarely quantifiable; (ii) public good quality is difficult to measure. We make progress on both fronts, exploiting a unique period of history in the Nigerian civil service, during which the activities of public bureaucracies were subject to detailed and independent scrutiny. During this period, quantitative information was collected to measure the actual implementation success and quality of public sector projects in various social sectors. The scrutineers were independent teams of engineers and members of civil society. We have hand coded this information to obtain assessments of completion rates for over 4700 public sector projects that began in 2006/7. The aggregate budget for these projects is US\$800 million or $8 \%$ of all social spending in Nigeria during our study period.

To measure the management practices that bureaucrats operate under, we follow the methodological approach of Bloom and Van Reenen [2007, 2010]. We adapt their management surveys to the Nigerian public sector setting, taking account of insights from the public administration literature [Rose-Ackerman 1986, Wilson 1989]. We collected data on management practices for 63 organizations of the Federal Civil Service in Nigeria, including central ministries and regional development authorities. For each organization we measure management practices related to: (i) the autonomy provided to bureaucrats; (ii) the provision of incentives and monitoring of bureaucrats.

The autonomy index captures the extent to which: (i) bureaucrats input into policy formulation

and implementation processes; (ii) the flexibility with bureaucrats can be reorganized to respond to 
best practice and project peculiarities. There are long-standing views in the public administration literature on the importance of autonomy. As Rose-Ackerman [1986] describes, at one extreme lies the view that public agencies ought to delegate as much decision making to bureaucrats as possible, relying on their professionalism and resolve to deliver public services [Simon 1983]. At the other extreme lies the Weberian view that, because the objectives of bureaucracies and society diverge, only an entirely rules-based system of public administration, that leaves little to the individual judgement of bureaucrats, can ensure consistent and acceptable levels of public service.

The incentives/monitoring based management index captures the extent to which an organization collects indicators of project performance, how these indicators are reviewed, and whether bureaucrats are rewarded for achievements reflected in these indicators. Incentive theory stresses the positive impacts performance incentives and monitoring have on organizational performance. However, a priori the impacts of such incentives in public sector settings is uncertain because: (i) bureaucrats might need to exert multiple effort types, not all of which are measurable; (ii) the process by which inputs are converted to outputs is uncertain; (iii) there can be competing views on the right way to implement bureaucratic outputs; (iv) bureaucratic objectives are not clear cut; (v) performance incentives might crowd out the intrinsic motivation of those self-selected into the public sector [Perry and Wise 1990, Benabou and Tirole 2006, Francois and Vlassopoulos 2008]. ${ }^{1}$

We probe these issues by exploiting a third data source: a survey we fielded to a representative sample of 4100 civil servants, corresponding to $13 \%$ of the total workforce of the 63 organizations we study. This asked bureaucrats about their tenure, employment history, intrinsic motivation, and perceptions of organizational corruption. We use this to shed light on how the impacts of management practice vary with bureaucrat characteristics.

Our empirical research design exploits the fact that multiple organizations conduct similar project activities. For example, small-scale dams are constructed by the federal ministries of water, agriculture, and environment. We therefore assess how the delivery of the same project type varies depending on the management practices in place for bureaucrats in the specific organization responsible, holding constant project characteristics, such as their technical complexity and scale, as well as the characteristics of organizations and bureaucrats. We use this empirical framework to present three findings relating civil service management practices and public service delivery.

First, management practices for bureaucrats matter. Despite the measures of management practice related to autonomy and incentives/monitoring being positively correlated, they have $o p$ posing correlations with public services delivered: a one standard deviation increase in autonomy

\footnotetext{
${ }^{1}$ Evidence is lacking on whether incentives positively impact bureaucrat behaviors [Perry et al. 2009, Hasnain et al. 2012]. Muralidharan [2012] discusses why performance pay might be suboptimal in the public sector. Positive impacts of performance pay for front-line teachers have been documented using RCTs in developing countries by Glewwe et al. [2010], Muralidharan and Sundararaman [2011], and Duflo et al. [2012], although Fryer [2013] finds zero/negative impacts in the US. In health, a nascent literature documents positive impacts of performance pay on frontline workers in developing countries [Miller and Babiarz 2013]. In line with our findings, Ashraf et al. [2014] document how non-monetary incentives elicit more effort than monetary incentives for such tasks.
} 
for bureaucrats corresponds to significantly higher project completion rates of $18 \%$, and a one standard deviation increase in practices related to incentives/monitoring corresponds to significantly lower project completion rates of $14 \%$. We find management practices correlate to quality-adjusted project completion rates in similar ways. The backdrop to these findings in Nigeria, where $38 \%$ of public projects are never started, implying these magnitudes are also of economic significance.

Our findings on autonomy for bureaucrats provide support to the notion that public agencies ought to delegate some decision making to bureaucrats, relying on their professionalism to deliver public services. The evidence is less supportive of the notion that when bureaucrats have more agency, they are more likely to pursue their own objectives or engage in corrupt activities, resulting in fewer public services being delivered. As discussed throughout, this is especially insightful in a context such as Nigeria, where corruption (at all tiers of government bureaucracy) is typically considered a major impediment to economic development.

Obviously, we are careful to describe our findings as partial correlations throughout. However, to support a causal interpretation, we document the determinants of management practices and examine channels through which organizations might endogenously adjust management practices. We find that the practices in place are largely driven by the education levels of the most senior bureaucrats. Reassuringly, we find little evidence of direct feedback effects of project completion rates on management practices, and nor do we find evidence of organizations endogenously adjusting management practices: (i) when it is easiest for them to do so because the portfolio of projects they are tasked to implement are more similar; (ii) when a greater share of the organization's budget is devoted to the successful implementation of the kinds of projects we study.

The robust negative correlation documented between project completion rates and management practices related to the provision of incentives and monitoring of bureaucrats, is also surprising and counter to a large body of evidence from private sector settings. We investigate three underlying mechanisms for this: that bureaucrats operate in a multi-tasking environment [Holmstrom and Milgrom 1991], that the incentives/monitoring management practices pick up subjective performance evaluation (SPE) [Milgrom 1988, Milgrom and Roberts 1988], and that incentives/monitoring crowd out bureaucrats' intrinsic motivations [Perry and Wise 1990, Benabou and Tirole 2006, Francois and Vlassopoulos 2008]. We investigate all three channels by examining how the impacts of incentive/monitoring related management practices vary with project, organizational and bureaucrat characteristics.

We document the negative correlation between these practices and project completion rates is even more negative for: (i) more complex projects; (ii) project types that are of greater ambiguity/uncertainty in design. Moreover, we find the negative impacts of performance-incentive practices are ameliorated in organizations with better IT facilities, that might reflect a greater ability to measure/target incentives towards more productive efforts. These findings are in line with bureaucrats having to exert multiple effort types, and incentives/monitoring practices being mis-targeted [Kelman 1990]. We also find the negative correlation between incentives/monitoring 
practices and project completion rates is more negative in organizations staffed by less experienced bureaucrats, that might reflect civil servants learning how to engage in influence activities when subject to SPE. Finally, on the interplay between incentive/monitoring management practices and bureaucrat motivations, we find the negative impact of incentives/monitoring is offset by the share of intrinsically motivated bureaucrats in the organization. Hence, if anything, this suggests crowding-in of bureaucrat effort in the presence of practices related to incentives/monitoring.

While the recent economics literature has emphasized the role of intrinsic motivation, a longstanding literature in public administration emphasizes that civil servants pursue their self-interest [Tullock 1965, Wilson 1989]. Our earlier finding, that granting bureaucrats more autonomy is positively correlated to higher project completion rates, already runs somewhat counter to this view. However, our final set of results probe this notion further by exploring how the impacts of management practices are mediated through perceptions of corruption among civil service organizations. Clearly, in the Nigerian context, the issue of corruption cannot be ignored, and it permeates throughout our analysis. We find a large negative levels impact on completion rates of corruption, but the impacts of management practices related to either autonomy or incentives/monitoring do not vary with perceptions of corruption. This suggests corruption is prevalent, but there are few bureaucrats on the margin of being prevented from behaving corruptly because of incremental changes in management practice (at least for the scale of public projects we consider).

The core contribution of our analysis is to supply novel evidence on how management practices for bureaucrats in civil service organizations correlate to public service delivery. We provide among the first pieces of empirical analysis of the functioning of this vital middle-tier of the bureaucracy, that has wide-reaching implications for research from both a macro and micro perspective. We extend the frontier of research on bureaucracies by overcoming data constraints that have limited earlier work, including on the measurement of the quantity and quality of public services provided, and extending techniques to measure management practices into the realm of bureaucracies. Our results point to new directions for theoretical research to better understand the contracting environment in public bureaucracies [Dixit 2002], as well as highlighting areas in which better measurement of inputs and outputs of public sector organizations can aid our understanding of public service delivery and state capabilities in the developing world.

The paper is organized as follows. Section 2 overviews relevant aspects of the Nigerian civil service. Section 3 details our data sources and empirical method. Section 4 presents our results linking public service delivery and management practices for bureaucrats. Section 5 concludes by discussing optimal management practices, presenting evidence on management practices and bureaucrats' time use, and links our findings to the literature on improving public services. The Appendix presents further data description, robustness checks and discusses econometric concerns. 


\section{Institutional Background}

Nigeria is Africa's most populous country, home to 160 million or $20 \%$ of the population of subSaharan Africa. Like other developing countries, government expenditures represent a significant fraction of GDP (26\%), it has generally weak institutions holding government to account, and corrupt practices in public sector organizations are commonplace. The British colonial government fashioned its Nigerian administration after the British Parliamentary Civil Service System, and this is what passed to an independent Nigeria in 1960. Despite moving to a Presidential system, Nigeria's civil service structure still largely replicates its British colonial origins. ${ }^{2}$

\subsection{Civil Service Organizations}

The Nigerian civil service is organized into federal, state, and local government tiers. Our analysis relates exclusively to the federal civil service. ${ }^{3}$ Table A1 lists the 63 federal civil service organizations we study. These include ministries of health, education, environment, and water resources, and organizations that have regional bases (such as federal polytechnics, federal medical centres, development authorities etc.). Table A1 highlights how these organizations vary in budget, staffing and decentralization. Federal ministries have the largest budgets and most staff as expected, with regional organizations being deconcentrated from central government. ${ }^{4}$

Each civil service organization is tasked to provide various types of project. These include construction projects (boreholes, buildings, roads and canals), as well as non-construction projects (procurement, training, and advocacy). For any given project type, multiple organizations are observed being tasked to implement similar projects. For example, small-scale dams are constructed by the federal ministries of water, agriculture, and environment, and by all of the river basin development authorities. We therefore assess how the delivery of the same project type is partially correlated to the management practices for bureaucrats in the organization responsible, holding constant other project, bureaucrat and organizational characteristics.

Underlying our analysis is the notion that civil service organizations place some weight on raising project completion rates: this is likely to be the case because, on average, $79 \%$ of the capital expenditure of organizations is related to the kinds of projects we study, and completion of these capital projects is often explicitly stated as part of organizations' core mission.

\footnotetext{
${ }^{2}$ The 1999 Constitution has similarities with the US Constitution: legislation is enacted by a bicameral National Assembly composed of the Senate and House of Representatives. Although the introduction of a Presidential system of government in 1979 saw initial reforms to the civil service, later decrees reversed some of these changes.

${ }^{3}$ The Civil Service is governed by a set of Public Service Rules and Financial Regulations, ad hoc Circular Instructions, decrees circulated across government, and Gazette Notices (decrees published in the Government's gazette). These outline the laws regulating the business of government, and cover service appointments, exits, discipline, salaries, and other major aspects of official assignments.

${ }^{4}$ Budget figures are 2006-10 averages. Staff numbers are from 2010. Deconcentrated organizations have boards of governors that decide policy/operations, and have a separate budget line to central ministries. Concentrated organizations have a direct line of responsibility to the President and National Assembly.
} 


\subsection{The Assignment of Civil Servants and Projects to Organizations}

The Head of the Civil Service of the Federation organizes the postings and conditions of Nigeria's federal civil servants. Our representative survey of 4100 individual civil servants confirms this: $88 \%$ of bureaucrats report having no influence over their initial posting, and $60 \%$ report their current posting being 'at random'. Once posted, civil servants enjoy job security. Our survey reveals mean tenure at the current organization to be 13 years, rising to 16 years for senior managers (those above grade level 12). Movements across organizations are rare: $67 \%$ of bureaucrats report never having moved organization. This lack of mobility in the labor market for bureaucrats slows down the rate at which best practices for management spread through the civil service, and dampens incentives for organizations to tailor management practices to attract certain types of bureaucrat.

Projects are assigned to organizations centrally by the National Assembly, that enacts a budget law specifying the projects to be implemented each fiscal year. The projects we study were all established in law by Budget Appropriation Bills in 2006 or 2007. This legal document defines the responsibilities of civil service organizations in terms of projects to be delivered. ${ }^{5}$

In the Appendix we present more detailed evidence on the factors determining the assignment of bureaucrats and projects to organizations, and document how both assignment processes are largely uncorrelated to the management practices in place in organizations.

\section{Data and Empirical Method}

\subsection{Project Completion, Quality and Complexity}

The Nigerian Government began a program of sweeping reforms in the major organs of government in 2003 [Nkonjo-Iweala and Osafo-Kwaako 2007]. As a result, it received cancellation of US $\$ 18$ billion of external debt from the Paris Club. At the federal level, the annual savings from debt interest were channeled into the social sectors we study. The Presidency saw this as an opportunity to track the effectiveness of government expenditures, and so in 2006 and 2007 the Nigerian Government undertook the Overview of Public Expenditure in NEEDS, known as the 'OPEN initiative', in which it traced, by project, the use and impact of $10 \%$ of all federal Government social sector expenditures approved in 2006 and 2007. The projects selected to be part of the OPEN initiative were to be representative of existing social sector expenditures, but also informative for

\footnotetext{
${ }^{5}$ The passage of these bills is as follows. Having received inputs from the executive branch of government, a draft Appropriation Bill is presented to the National Assembly. The draft bill is then split into sectors and sent to sectoral committees of the House and Senate. These committees hold hearings with relevant parties to scrutinize proposals, define project budgets and assign projects to organizations. These committees are staffed by politicians with qualifications/experience in the relevant sector. These committees then recommend a budget for the sector to an Appropriation Committee which merges the recommendations into a single budget. This unified budget is then voted on by both houses to form the Budget Appropriation Bill.
} 
those projects most needing to be scaled-up nationwide. ${ }^{6}$

Under the OPEN initiative, expert teams visited public projects to record the extent to which they had been implemented as planned in the Federal Budget. The Presidency contracted national and regional teams to undertake the monitoring process outside of the institutions of the civil service. Hence projects were not evaluated by potentially biased civil servants, but rather by teams of independent engineers and civil society. To further ensure the accuracy of monitoring reports, the Presidency put in place a system of checks and balances. First, a centralized team of technocrats monitored the evaluation teams, and providing them with training and opportunities for standardization of their methods. Second, evaluators were asked to provide material, photographic, or video evidence to support their reports. Third, the national teams and Presidency performed random checks on evaluated sites. Evaluations of the OPEN process indicate it successfully achieved its aims [Eboh 2010, Dijkstra et al. 2011]. ${ }^{7}$

We consider projects traced under the OPEN initiative that were approved in the 2006/7 federal budgets [Federal Government of Nigeria 2008, 2009]. Monitoring teams visited project sites 18 months after the project was centrally approved. All the projects we study have 12 month completion schedules, so that even accounting for any delay in the disbursement of funds, it is feasible for these projects to be completed by the time of the monitoring survey. We hand coded the material from all projects recorded in OPEN initiative reports from the federal civil service organizations listed in Table A1. ${ }^{8}$ Taken together, the coverage of projects in our sample traces $8 \%$ of all Federal Government social sector expenditures in 2006/7 budget years, corresponding to 4721 projects from 63 organizations, with an aggregate budget of around US\$800 million.

The OPEN evaluation teams coded: (i) whether the project had started; (ii) its stage of completion; (iii) the quality of inputs and work. Our main outcome variable is a continuous zero to one measure of project completion rates, available for all 4721 projects. A completion rate of zero does not imply the organization never even attempted to work on the project. Rather, the

\footnotetext{
${ }^{6}$ Table A2 shows the distribution of expenditures in the Nigeria federal budget across the social sectors as a whole (Column 1), for all projects in the OPEN initiative (Column 2) and in our sample of OPEN projects (Column 3 ). This is done for all social sectors with the exception of the Works Sector (that covers trunk roads and constitutes $5 \%$ of total social sector expenditure in the federal budget), because the OPEN data we use does not cover that sector. The share of OPEN projects by sector matches closely the distribution of expenditures as a whole. A Chi-squared test of equality of shares across sectors does not reject the null. Evidence from process overviews of the OPEN initiative, including qualitative evidence from local communities on their perception of projects, suggests the projects included in the OPEN initiative were thought to be welfare improving [OPEN report for North East Nigeria 2006, the Civil Society Organizations Monitoring and Evaluation Report 2007].

${ }^{7}$ Prior to the OPEN initiative, the government had its own monitoring and evaluation systems in place (based on unannounced visits) but these were largely perceived to be ineffective. When OPEN was introduced, OPEN projects were processed through the same standard government channels as non-OPEN projects, and so overall, there was no ex ante reason to believe it would be much more effective than the previous monitoring regime. This helps ameliorate concerns that our results pick up a Hawthorne effect in response to the OPEN initiative.

${ }^{8}$ In the water and power sectors, we cover all the relevant federal organizations. In the health sector, we cover $28 \%$ of health organizations, with the excluded a subset of the medical service providers such as a number of Federal Medical Centres. Similarly, in education we cover $14 \%$ of education organizations, excluding a range of institutions of learning such as some Federal Colleges of Education.
} 
project might have been prepared, with responsibility for implementation having been delegated to a department and bureaucrats within the organization. At that point however, progress on the project halted, with funds either being returned due to lack of use, or being lost. We cannot distinguish whether this lack of implementation reflects active or passive waste [Bandiera et al. 2009]. A completion rate of one implies the project matched its full technical specification.

To maximize coverage on project quality, we utilize the most aggregate formulation of quality reporting. A project was either of insufficient quality, satisfactory, or commended for an 'above average or high' quality level: 2206 projects have both quality and completion rates recorded.

Table 1 provides descriptive evidence by project type. Boreholes are the most common, covering $29 \%$ of OPEN projects. Most project types are implemented by a range of organizations. There are, for example, 18 civil service organizations constructing boreholes (Column 2). Hence we study the impact of management practices for bureaucrats, that vary across civil service organizations, on project implementation, conditional on project-type fixed effects. Column 3 highlights the scale of projects: most constitute the 'nuts-and-bolts' of rural infrastructure development. The median budget for dams is US $\$ 18,000$, the median budget for a building is US\$120,000. It is because projects are relatively small-scale that partly explains why multiple organizations are observed being tasked to implement similar project types. Columns 4 to 7 show completion rates by project type, emphasizing variation in completion rates across and within project types. Aggregating across all project types, 38\% of projects are never started. Although this might emphasize the role that corruption or passive waste plays, it is not a complete explanation for bureaucrat behavior: $31 \%$ of projects are fully completed, and conditional on being started, the average project completion rate is .75 . Column 8 shows, across project types, the majority of projects are ranked to be of satisfactory quality.

Table 2 presents descriptive evidence on the public service delivery of the ten civil service organizations that implement the most projects in our sample. This again emphasizes that most organizations are engaged in providing multiple project types. We observe huge variation across these large organizations in the percentage of projects that are never started (11\% to 95\%), and that are fully completed ( $3 \%$ to $89 \%$ ). The final column shows the percentage of projects rated to be of satisfactory quality: here we observe far greater variation across civil service organizations ( $25 \%$ to $100 \%$ ) than we previously documented in Table 1 across project types.

These statistics suggest there might be important factors at the organization level that drive this variation in the quantity and quality of public service delivery. Our focus is on one such factor: the management practices civil service bureaucrats operate under.

When relating project outcomes to management practices for bureaucrats, it is important to condition on project complexity [Prendergast 2002]. To measure this we collaborated with a pair of Nigerian engineers familiar with the OPEN initiative and a group of international scholars with research interests in project complexity. The complexity indicators were based on the technical specifications of each project, and constructed following engineering best practice that emphasizes 
multiple dimensions of complexity [Remington and Pollack 2007]. The Appendix: (i) details the construction of these indices, and presents descriptive statistics for them (Table A3); (ii) describes checks in place, using multiple engineers, to underpin the validity of our complexity measures. ${ }^{9}$

These complexity indicators reflect the number of inputs and methods needed for the project, the ease with which the relevant labor and capital inputs can be obtained, ambiguities in design and project implementation, and the overall difficulty in managing the project. Our empirical specification then holds constant the complexity of the project along these dimensions, including issues related to organizations needing to sub-contract project implementation to a private sector firm, for example. This allows us to focus in on the correlation between managerial practices for bureaucrats and project completion rates, all else equal. ${ }^{10}$

\subsection{Measuring Management Practices}

There has been a revival of interest in studying management practices in the private sector [Ichniowski et al. 1997, Black and Lynch 2001, Bloom and Van Reenen 2007, 2010; Bloom et al. 2012a, 2013]. We follow Bloom and Van Reenen's (henceforth BVR) approach to measuring management practices, but adapt their survey tool to the Nigerian public sector setting by taking into account long-standing views on the importance of autonomy in public administration [Simon 1983, RoseAckerman 1986, Wilson 1989] and insights from the 'new performance management' and 'good governance agenda' perspectives [Francois and Vlassopoulos 2008, Goldfinch et al. 2012].

We worked closely with members of the OPEN office in the Presidency and the Office of the Head of the Civil Service of the Federation to develop our management survey. A number of pilots using semi-structured interviews like those in BVR were held to outline key similarities and deviations from the BVR methodology. The management survey enumerators were trained together for a number of weeks including practice interview sessions before undertaking the first few interviews together. Information on management practices was then elicited from senior management staff in the key departments of each organization, but not the chief executive officer. While each manager filled in their own questionnaire, the enumerator looked for a consensus and recorded that in her own questionnaire. This is the information we use to construct management practice indices for each organization. ${ }^{11}$

\footnotetext{
${ }^{9}$ Prendergast [2002] also implies that autonomy and incentives are both positively correlated to task uncertainty/complexity. We find: (i) CS-autonomy is positively correlated to project complexity (averaged across all projects in the organization), with correlation coefficient .05; (ii) however, CS-incentives/monitoring is negatively correlated with project complexity. in In an extension to the baseline model, Prendergast [2002] discusses how incentive provision and uncertainly/complexity can be negatively correlated in equilibrium if multi-tasking concerns are greater in more uncertain environments. This prediction matches well with the evidence we provide later, highlighting incentives/monitoring practices have a more negative impact on more complex and atypical projects.

${ }^{10}$ Our civil servant survey also helps to shed some light on the relationship between bureaucratic organizations and such third party contractors/suppliers/consultants. For example, only $6 \%$ of civil servants agreed with the statement that, the most successful contractors "are aligned with the government in some way"; only $13 \%$ of civil servants reported having been offered a 'small present', 'money', or an 'expensive present' by such contractors.

${ }^{11}$ Conducting face-to-face group interviews was judged to lead to more accurate answers than using telephone
} 
From September to November 2010, our survey team held interviews at the organizations listed in Table A1. Following BVR, interviews were 'double blind' in that: (i) managers were not told in advance they were being scored or shown a score grid; (ii) enumerators were given no information on the performance of the organization. The BVR evaluation tool elicits management practices through a semi-structured interview covering four topics: operations, targets, incentives and monitoring. We apply the BVR approach in the context of public bureaucracies, extending the series of practices elicited to cover those more relevant for managing bureaucrats. As a result, our management survey covers nine topics: roles, flexibility, incentives, monitoring, culture, targeting, facilities, skills and staffing. We then replicate the BVR method eliciting information on each of these broad topic areas from our civil service organizations, although we do so using a more limited set of underlying questions related to each topic, and some of our questions permit only yes/no replies, while others are based on a full scoring grid. Table A4 details the questions that come under each topic area. ${ }^{12}$

The questions on 'roles' assess the extent to which bureaucrats input into policy formulation/implementation processes. The 'flexibility' questions measure whether a bureaucratic agency is able to re-organize its bureaucrats and adapt tasks to respond to best practice and project peculiarities. We combine answers to the roles and flexibility questions to construct an index of management practices capturing bureaucrats' 'autonomy' (CS-autonomy). This allows us to study a key dimension of management that the public administration literature has long emphasized.

The questions on 'incentives' are designed to capture more familiar notions for economists of incentive provision for bureaucrats, both positively in terms of whether rewards are given for some dimensions of service, and negatively in terms of punishments for poor service; the questions on 'monitoring' capture practices related to the collection and use of performance indicators. We combine the answers to both topics to construct an index capturing the 'incentives/monitoring' management practices bureaucrats operate under (CS-incentives/monitoring).

The remaining topics cover the following practices: the 'facilities' questions relate to how wellfunctioning the organization is, for example, by collecting information on the availability of electricity and internet facilities to bureaucrats; the 'skills' questions relate to the human capital

surveys. Given the interview format, individual manager responses on management practices are available, but we cannot link individual managers to specific projects and so do not utilize that information (each project is delivered by teams of bureaucrats across sub-departments): rather we use the consensus measure recorded by the enumerator. Managers were told their individual responses would remain confidential. We find no relationship between recorded practices and the number of managers present at interview.

${ }^{12}$ Hence there are two important deviations from how we elicit management practices from BVR. First, we tailored the precise wording of some questions to better fit our context. Second, we did not use the same universe of questions from BVR. In most cases this was because we could not identify an analogous concept in the public sector that was relevant or not covered by other questions. For example, the majority of questions on lean manufacturing in BVR (e.g. 'What kinds of lean (modern) manufacturing processes have you introduced?') were not utilized. However, those on improving manufacturing processes ('How do you go about improving the manufacturing process itself?') were redefined to relate to procedures in response to new needs or challenges ('Does your organization make efforts to redefine its standard procedures in response to the specific needs and peculiarities of a community?'). 
of bureaucrats, especially their IT competencies, and the trainings offered to them; the 'staffing' questions focus staff recruitment and workload spreads; the 'targeting' questions relate to the existence and clarity of targets, and finally, the questions related to 'culture' elicit information on how colleagues are collectively treated and interact with others outside of the workplace. We combine answers on all these topics to construct an 'other' management practices index (CS-other).

We clearly recognize there is no definitive way to solicit management practices along these various dimensions, nor a definitive way to collate them into more aggregate indices. Our approach is primarily designed to reflect two broad areas of management practice emphasized in the public administration and economics literatures as being first order determinants of bureaucrats' behavior: autonomy and incentives/monitoring. The Appendix details our findings if we consider alternative indices including: (i) a fully disaggregated specification showing the separate impact of all nine dimensions of management practice; (ii) an aggregate measure of management practice that collates all nine categories into a single index; (iii) alternative groupings of individual practices into autonomy and incentive/monitoring measures. ${ }^{13}$

The responses to each practice in Table A4 are converted into normalized z-scores (so are continuous variables with mean zero and variance one by construction), where in all cases, variables are increasing in the commonly understood notion of 'better management'. For the CS-autonomy index, we assume greater autonomy corresponds to better management practices (our empirical analysis then assesses whether this is positively or negatively correlated to project completion rates), and similarly for the CS-incentives/monitoring measure. For our core analysis, we aggregate z-scores into the CS- measures by taking unweighted means of the underlying z-scores. In the Appendix, we show the robustness of our results to other weighting schemes.

We find the CS-autonomy and CS-incentives/monitoring management scores to be positively correlated (correlation coefficient .24), in line with the frameworks set out in Prendergast [2002] and Acemoglu et al. [2007]: that suggest in more uncertain environments it is optimal to grant agents more autonomy, that in turn, generates greater output-based incentive pay. Hence in the cross section of federal organizations, the provision of autonomy and performance incentives appear to be complements. However, these correlations are not so high to prevent precise estimation of the separate relationship of each measure to public service delivery. ${ }^{14}$

The gap between the collection of the OPEN data set in 2006/7 and the management survey in 2010 raises the question whether practices changed significantly in between data collection periods. For example, those organizations found to have low completion rates might have instigated reforms

\footnotetext{
${ }^{13}$ We have also used principle components analysis to assess the importance of individual practices through factor analysis. For the matrix of all nine sub-indices, we find the first factor explains $28 \%$ of the variation.

${ }^{14}$ Such substitution could exist if bureaucrats have strong career concerns, and so performance incentives are not required once autonomy is provided. Alternatively, if bureaucrats are intrinsically motivated they might need only to be provided autonomy, and indeed, the provision of explicit incentives might crowd out their intrinsic motivation. The marginal impacts of these two measures can also be separately identified from the CS-other index: the CS-autonomy (CS-incentives/monitoring) index has a correlation of .17 (.43) with the CS-other measure.
} 
to improve management practices for bureaucrats. However, there is little evidence from other sources of any major civil service reforms being implemented over this period, or of significant changes in the political organization of federal agencies [Alabi and Fashagba 2010, Ogundiya 2011]. In addition, we find little evidence of a spike in turnover of bureaucrats around 2007, coinciding with the Presidential election: $80 \%$ of bureaucrats employed in 2010 were at the same organization in 2007 (with retention rates around the election being higher among senior managers).

\subsection{Origins of Management Practices}

To understand how management practices come to be, we held structured interviews at four organizations in Table A1. These revealed three common themes: (i) the Public Service Rules of the Nigerian civil service provide guidelines on how bureaucrats should be incentivized, and these are common to all federal organizations; (ii) the history of senior management staff that have worked in an organization brings their own innovations to bear; (iii) the role of external events such as demands of trade unions. Taken together, these interviews consistently emphasized the slow evolution of management practices, and did not suggest practices were tailored to necessarily maximize public service delivery. ${ }^{15}$

More formally, we simultaneously estimate the correlates of each dimension of management practice using a SUR model, at the organizational level. We control for: (i) characteristics of senior bureaucrats, such as their years of schooling and tenure in the organization; (ii) the same characteristics for other bureaucrats; (iii) organization characteristics, such as its average project completion rate, whether it is a decentralized body, the average budget and complexity of projects assigned to it. Table 3 presents the results where three points are of note, that each bolster the interpretation of our main results as causal.

First, the provision of autonomy to bureaucrats is correlated to the education level of senior management, in line with the feedback we received during the structured interviews. The provision of incentives/monitoring is correlated with the education level of other bureaucrats. Second, average project completion rates do not predict management practices in place. This helps rule out concerns over reverse causation between project completion rates and management practices. Third, project characteristics, such as the average complexity of projects the organization is tasked to implement (or the standard deviation in project complexity), have no significant impact on either management practice. This addresses the concern that projects are selectively assigned to organizations on the basis of their management practices.

\footnotetext{
${ }^{15}$ Management practices in all organizations take the Public Service Rules as their foundation. These guidelines for the distribution of authority, how bureaucrats should be disciplined etc. In each structured interview, they were said to be central to determining management practice. However, we were repeatedly told a secondary influence on practices was the history of senior management at the organization. Officials are promoted into management positions based primarily on tenure. Views on management practices are typically aggregated by committee, with the chief executive marshalling the direction of reform. This leads to a relatively slow changing management environment. Finally, external events, such as the demands of trade unions, were said to have a third-tier influence.
} 


\subsection{Empirical Method}

Our baseline empirical specification has as its unit of observation project $i$ of type $j$ in organization $n$. Project types $j$ are listed in Table 1, and organizations $n$ are listed in Table A1. We estimate the following OLS specification, where $y_{i j n}$ is the project completion rate, and management practices are measured using the CS-autonomy, CS-incentives/monitoring and CS-other indices,

$y_{i j n}=\gamma_{1} C S$-autonomy $y_{n}+\gamma_{2} C S$-incentives $/$ monitoring ${ }_{n}+\gamma_{3} C S$-other ${ }_{n}+\beta_{1} P C_{i j n}+\beta_{2} O C_{n}+\lambda_{j}+\epsilon_{i j n}$.

$P C_{i j n}$ is a vector of project characteristics including project complexity, log project budget and whether the project is a rehabilitation or not. $O C_{n}$ is a vector of organizational controls such as the log number of staff, log total organization budget, log capital budget, and the proportions of officials with a college and postgraduate degree. Following BVR, within $O C_{n}$ we also condition on 'noise' controls related to the management surveys. ${ }^{16}$

As many organizations implement project type $j$, we control for project type fixed effects $\lambda_{j}$ in (1). Our parameters of interest are $\gamma_{1}$ and $\gamma_{2}$ : as each CS- measure is a standardized z-score, these coefficients measure the effect size of a one standard deviation change in management practices along the respective margins of autonomy and incentives/monitoring. We cluster standard errors by project type-organization, and the Appendix demonstrates the robustness of our results to allowing standard errors to be clustered by organization and correcting p-values for potential biases due to a small number of clusters [Cameron et al. 2008] (Table A5). Our working sample is based on 4721 projects from 63 organizations on which we have data on management practices and project, organization and bureaucrat characteristics. ${ }^{17}$

We are implicitly assuming that, within project type and controlling for project and organizational characteristics, the underlying production function is the same across projects. Specification (1) then corresponds to a reduced form representation of an underlying production function in which management practices convert the raw total of available bureaucratic labor into effective labor inputs in the completion of public projects. Along similar lines but in the context of profit maximizing firms, Bloom et al. [2014] formally develop and test the notion that management can be thought of as a form of technology, thus explaining between firm variation in productivity.

The coefficients of interest $\left(\widehat{\gamma}_{1}, \widehat{\gamma}_{2}\right)$ should be interpreted as partial correlations between management practices and project outcomes. However, we later address head on the concern that man-

\footnotetext{
${ }^{16}$ These include interviewer dummies, the seniority, gender, and tenure of the managers who responded, the day of the week and time of day of the interview, whether the interview was conducted during Ramadan, the interview duration, and an indicator of the reliability of the information as subjectively coded by the interviewer.

${ }^{17}$ Regressing project completion rates on organizational fixed effects yields an adjusted- $\mathrm{R}^{2}$ of .32 , suggesting that organizational characteristics such as management practices can plausibly play an important role in determining such outcomes. Regressing project completion rates on all project characteristics (including project fixed effects, but not our CS-measures or organization fixed effects), the adjusted- $\mathrm{R}^{2}$ is .11. Additionally controlling for organization fixed effects, the adjusted- $\mathrm{R}^{2}$ rises to .34 . These last two results suggest that conditional on project characteristics, it remains true that some organization level characteristics are important determinants of project completion rates.
} 
agement practices are endogenously determined by bureaucrat characteristics or project outcomes, by investigating whether organizations appear to be tailoring their practices in order to maximize project completion rates. In the Appendix we discuss further econometric concerns including: (i) projects being non-randomly assigned to organizations based on their management practices; (ii) unobserved bureaucrat or organizational characteristics that are correlated to management practices and also drive project completion rates. The conclusion discusses further methodological challenges for future research on the determinants of the bureaucratic effectiveness.

\section{Core Results}

\subsection{Project Completion Rates}

Table 4 presents our main results on how management practices correlate with project completion rates. Column 1 only controls for the three CS- measures. We find that the practice of giving greater autonomy to bureaucrats is correlated to significantly higher completion rates $\left(\widehat{\gamma}_{1}>0\right)$. The use of performance incentives/monitoring for bureaucrats however significantly reduces project completion rates $\left(\widehat{\gamma}_{2}<0\right)$. Columns 2 to 4 sequentially condition on noise controls and organizational characteristics, project characteristics, and project type fixed effects. Throughout, we find both management practices have highly significant impacts on project completion rates.

Our preferred specification is in Column 4 with project type fixed effects, $\lambda_{j}$. This shows a one standard deviation increase in CS-autonomy corresponds to significantly higher project completion rates of $18 \%$. A one standard deviation increase in CS-incentives/monitoring corresponds to significantly lower project completion rates of $14 \%$. In all specifications, better management practices on the CS-other dimension are positively correlated with project completion rates; in Column 4 the estimated coefficient is indeed significant at conventional levels, although the effect size is significantly smaller than for the two dimensions of management practice.

Columns 5 and 6 consider alternative outcome measures. Column 5 focuses attention on how management practices correlate to the extensive margin of projects being started (as Table 1 showed, $38 \%$ of projects have a zero completion rate). Hence the outcome considered is a dummy equal to one if the project completion rate is strictly positive, and zero otherwise. We see that each dimension of management practice has qualitatively similar impacts on whether projects are started or not, as on the total project completion rate focused on in Columns 1-4. In Column 6 we address the concern that projects may be almost completed but to a low quality. We therefore construct a 'quality-adjusted' completion rate where the proportion completed is multiplied by a binary quality indicator. Where quality is unsatisfactory, whatever the level of completion, this variable is set to zero. As described in Section 3, information on project quality is only available for around half the projects for which we have project completion data, originating in 51 civil service organizations. Column 6 then shows the relationship between management practices and 
quality-adjusted project completion rates. We find the CS- measures to quantitatively impact quality-adjusted project completion rates in a similar way to project completion rates: higher levels of CS-autonomy are associated with significantly higher quality projects, and higher levels of CS-incentive/monitoring are associated with significantly lower quality projects.

\subsection{Endogenous Management Practices}

The central empirical concern with these baseline results relates to endogenous management practices. If for example some organization completes projects because they employ more dedicated civil servants, they might then endogenously choose to give those bureaucrats more autonomy, and be less reliant on the use of incentives/monitoring. On the other hand, in those organizations staffed by less reliable bureaucrats, the organization might choose to monitor and incentivize them along some margins, and allocate them less autonomy. This is the econometric concern that most plausibly generates the pattern of positive and negative partial correlations in our core results. We use two strategies to address this concern.

Our first approach identifies organizations that have the greatest incentives to fine tune their management practices to maximize project completion rates. Such organizations are those in which the completion of projects is relatively more important in their set of overall activities, as proxied by the share of the organization's total budget assigned to capital expenditures (such as those on OPEN-style projects). We then estimate a specification analogous to (1) and additionally interact each CS- measure with this measure of 'project importance' (defined in terms of its deviation from mean), also conditioning on the organization's log total budget. If management practices are endogenously determined through this channel, their impacts should be attenuated for organizations in which it is more important to fine tune practices to maximize completion rates. The result in Column 1 of Table 5 shows no evidence of such heterogenous impacts.

Our second approach identifies those organizations that have the most similar portfolio of projects to implement, as measured by project ambiguity. Such organizations might have the greatest ability to set their management practices optimally. To implement this test, for each organization we first need to construct the variance in project ambiguity over all its assigned projects. We measure the design ambiguity of a given project using subcomponents of the complexity indicator described in Table A3. We construct a z-score based on the design uncertainty, implementation uncertainty, design ambiguity and implementation ambiguity components of the project complexity metric, and then denote the ambiguity of project $i$ by $\sigma_{i}$. We then construct the standard deviation of project ambiguity of projects assigned to organization $n, s d\left(\sigma_{i}\right)_{n}$, and then interact this with each management practice measure to estimate whether the impacts of the CS- measures of interest are attenuated among those organizations that have the more similar projects in terms of their design ambiguity. The result in Column 2 of Table 5 shows there to be no evidence of such heterogenous impacts. Indeed, the key interaction terms have precisely 
estimated zero point estimates.

Taken together with the evidence in Table 3 on the origins of management practices, we view this lack of evidence of organizations manipulating their practices to raise completion rates, as underpinning a causal interpretation to our findings.

\subsection{Robustness Checks}

The Appendix presents a series of robustness checks to examine the stability of our core finding to alternative samples, variable definitions and econometric methods.

We first addresses the concern that the underlying production function for project completion differs across project types. To do so we restrict attention solely to borehole projects (that are the modal project type), and Appendix Table A6 then replicates the sequence of specifications in Table 4. This shows that when only borehole projects are considered, the coefficients of interest $\left(\widehat{\gamma}_{1}, \widehat{\gamma}_{2}\right)$ remain the same sign and significance as in our main specifications presented in Table 4.

We next document the robustness of our baseline result along eight further margins (as shown in Tables A7 and Figure A1): (i) defining threshold completion rates that deem the project usable and seeing how management practices relate to reaching these thresholds; (ii) restricting the sample to the largest/smallest organizations; (iii) removing organizations at the tails of the CSmeasures; (iv) considering the impacts of managerial practices on construction/non-construction projects separately; (v) considering the impacts of managerial practices on projects implemented by centralized/decentralized organizations separately; (vi) controlling for characteristics of the state in which the project are located, and exploring how the results vary depending on whether projects are located in the North or South of the country that defines the principal cultural divide in Nigeria; (vii) alternative constructions of the CS- indices (rather than the equal weighting procedure); (viii) using a fractional regression model.

Given the fact that methodologically, there is no definitive way to group individual practices into management indices related to autonomy and incentives/monitoring, in Appendix Table A8 we consider the robustness of our results to alternative groupings of practice into these two dimensions. We consider changes to both CS- indices, as well as considering an alternative breakdown of the CS-incentives/monitoring index, grouping practices that match more closely to input- or outputbased incentive measures. Taken together, the results show that small changes to the construction of management practice indices we focus on, does not change the substantive conclusions reached earlier from Table 4. In Appendix Table A9 we further examine the impacts of all nine dimensions of management practice on project completion rates.

In Appendix Tables A10 to A12 we discuss other econometric concerns and assess their potential severity. These concerns focus on: (i) projects being non-randomly assigned to organizations based on their management practices; (ii) unobserved organizational or bureaucrat characteristics that are correlated to management practices and also drive project completion rates. 


\subsection{Exploring the Negative Impact of Incentives/Monitoring}

Our core results from Table 4 confirm that the two dimensions of management practice emphasized by the public administration and economics literatures, namely autonomy and incentives/monitoring, do indeed correlate to the quantity and quality of public services delivered. The positive correlation of CS-autonomy with project completion rates supports the notion that public agencies ought to delegate some decision making to bureaucrats, relying on their professionalism and resolve to deliver public services. The evidence is less supportive of the notion that when bureaucrats have more agency, they are more likely to pursue their own, potentially corrupt, objectives that diverge from societal interests.

The robust negative correlation between project completion rates and management practices related to the provision of incentives and monitoring of bureaucrats, is far more surprising and counter to a large body of evidence from private sector settings. As described in the introduction, the evidence on the impacts of performance-related incentives in public sector settings is mixed (often focusing on the impacts of specific compensation schemes to frontline workers). ${ }^{18}$ Ours is among the first evidence to suggest the possibility that such management practices have negative impacts on the vital tier of civil service bureaucrats. Given the novelty and importance of this finding, we now investigate the result in more detail.

The detrimental impacts of such practices for bureaucrats might operate through at least three mechanisms. First, bureaucrats might operate in a multi-tasking environment, exerting some types of effort that can be labelled as 'processing', that do not lead to project completion rates, and also exerting more productive types of effort that raise completion rates. Our management practice measure might then capture an incentive system that places excessive regulatory burden or 'red tape' on bureaucrats that has long been argued to lead bureaucrats to mis-allocate effort towards processing activities [Kelman 1990]. Alternatively, our management practices related to incentives/monitoring might pick up subjective performance evaluation (SPE). While SPE has the benefit of being based on a more rounded set of assessments, such subjective assessments also give rise to other biases and dysfunctional responses, especially the desire of agents to engage in influencing activities to curry favor with supervisors [Milgrom 1988, Milgrom and Roberts 1988]. If so, the increased use of such mis-targeted incentives and key performance indicators can also lead to bureaucrats reallocating effort towards non-productive tasks, reducing project completion rates. Finally, performance incentives might crowd out the intrinsic motivation of bureaucrats [Perry and Wise 1990, Benabou and Tirole 2006, Francois and Vlassopoulos 2008]. ${ }^{19}$

\footnotetext{
${ }^{18}$ In health, two recent Cochrane reviews have come to different conclusions on the efficacy of pay for performance [Flodgren et al. 2011, Scott et al. 2011]. Perry et al. [2009] review 57 studies on pay for performance in the public sector and conclude 'pay-for-performance continues to be adopted but persistently fails to deliver'. Hasnain et al. [2012] review over 60 public sector studies, and find the vast majority are for tasks where outputs are more easily measurable such as teachers, health workers, and revenue inspectors. They argue there is simply insufficient evidence of the impact of incentives on bureaucrats.

${ }^{19}$ Baker [2002] develops a multi-tasking model to characterize how distortion and risk affect the value and use
} 


\subsubsection{Multi-tasking and Incentive Design}

We use three strategies to investigate this channel. We first check whether the partial correlation of incentives/monitoring practices with project completion rates varies with the complexity of projects, assuming: (i) more complex projects require more varied effort types to be exerted; (ii) incentives are harder to design for such projects, all else equal. Column 1 in Table 6 interacts the CS-incentives/monitoring measure with the continuous measure of project complexity. For expositional ease, this interaction term is defined in terms of its deviation from mean, so the coefficients on CS-autonomy and CS-incentives/monitoring are interpreted as the marginal effect of these practices, evaluated at the mean of project complexity. We see the negative impacts of CS-incentives/monitoring practices for bureaucrats are exacerbated in more complex projects, in line with a multi-tasking interpretation.

Our second approach to understanding whether incentive/monitoring schemes might be poorly designed in this setting uses the intuition that if the negative impacts of incentives/monitoring reflects the inability of organizations to correctly target such incentives to the relevant types of bureaucrat effort, this problem might be ameliorated in organizations with better IT facilities, who presumably have better capability to objectively measure effort types [Bloom et al. 2012b]. To explore this we interact our CS-incentives measure with the CS-facilities dimension of management practice: as Table A4 shows, this relates to the availability of computing facilities at the organization. In this specification we redefine CS-other to exclude the CS-facilities component. The result in Column 2 of Table 6 indeed shows the impacts of CS-incentives to be significantly less negative in organizations with better IT facilities. Moreover, there is no significant levels impact of CS-facilities: the provision/accessibility of IT facilities for bureaucrats only seem to matter in combination with management practices related to incentives/monitoring.

A third approach to examine the role multi-tasking might play exploits information on the inherent riskiness/ambiguity of projects as embodied in their technical specifications. Incentives/monitoring practices might be harder to tailor for more ambiguously designed projects, all else equal. To explore this, we consider projects of different types $j$ to be of systematically different design ambiguity, and proceed in two steps. First, we measure this design ambiguity using subcomponents of the complexity indicator described in Table A4. We construct a z-score based on the design uncertainty, implementation uncertainty, design ambiguity and implementation ambiguity components of the project complexity metric. Denote the average ambiguity of projects of type $j$ by $\bar{\sigma}_{j}$. We then estimate a specification analogous to (1) for a given project type $j$ (excluding project type fixed effects). In our sample, there are sufficient numbers of projects implemented across different organizations to estimate this for five project types: boreholes, buildings, dams, procurement and training. For each project type $j$ we then obtain an estimate of

of performance measures. The model highlights how in public bureaucracies, that cannot use stock incentives and have nebulous objective functions, leading to a fundamental difficulty in defining 'good' performance measures. Hence the potential for dysfunctional responses when high powered incentives are utilized in such settings. 
the partial correlation between CS-incentives and project completion rates, $\widehat{\gamma}_{2 j}$, conditional on CS-autonomy. Figure 1 plots the five $\left(\widehat{\gamma}_{2 j}, \bar{\sigma}_{j}\right)$ pairs, as well as a cubic best fit.

The evidence suggests the deleterious impact of incentives/monitoring practices on project completion rates is worse for projects with greater inherent design ambiguity. ${ }^{20}$ Projects with the greatest design ambiguities might be those for which incentives/monitoring schemes are hardest to tailor, and so illicit the most dysfunctional responses from bureaucrats. The heterogenous impacts documented across project types in Figure 1 also provides an explanation of why there are such mixed empirical findings in the literature on the impact of incentive provision in public sector settings: different studies might have considered projects/tasks of differing complexity and design ambiguity. Finally, we note the average ambiguity of project types $\bar{\sigma}_{j}$ correlates with the proportions of those projects that have completion rates of zero: this suggests bureaucrats might simply shy away from implementing the most ambiguously designed projects to begin with.

\subsubsection{SPE and Intrinsic Motivation}

To shed light on the plausibility of these channels driving the effects of incentives/monitoring practices, we consider how these practices interplay with bureaucrat characteristics, as measured through the survey we administered to a representative sample of officials at each organization. As described in Section 2, Nigerian bureaucrats enjoy long tenure. On the one hand, longer serving bureaucrats might learn how best to respond to incentives by exploiting other flexibilities. On the other hand, if bureaucrats are subject to SPE they might learn how best to engage in influence activities. To check for this, Column 3 in Table 6 controls for an interaction between the average tenure of bureaucrats in the organization (in deviation from mean) with the CSincentives/monitoring measure, as well as the direct impact of tenure. We find the negative impacts of incentives/monitoring are even worse in organizations staffed by more experienced bureaucrats, consistent with bureaucrats learning how to engage in influence activities. We also note there is no direct levels effect of average tenure on project completion rates, so that it is not the case that bureaucrats naturally reduce effort over time as they become embedded within long-standing norms of poor standards in civil service organizations. Rather, there appears to be a specific interplay between bureaucrat tenure and incentives/monitoring practices for bureaucrats.

A burgeoning literature suggests those attracted to public service might be relatively more intrinsically motivated than those working in the private sector. Performance incentives might then be detrimental if they crowd out such intrinsic motivation. To measure civil servant's intrinsic motivation, we asked bureaucrats which factor that had most influenced them to originally enter the civil service from the following options: 'I was interested in the type of work', 'income prospects', 'the prestige associated with such a job', 'the stable career path that a job in the service affords',

\footnotetext{
${ }^{20}$ Given the CS-performance and CS-autonomy are positively correlated and have opposite signed impacts on project completion rates, this negative relationship between risk/uncertainty and incentives would be attenuated if we do not control for CS-autonomy when estimating $\widehat{\gamma}_{2 j}$ [Prendergast 2002].
} 
'the chance to serve Nigeria', 'it was the only employment I could get', 'educational opportunities', 'other'. We define those that answered, 'the chance to serve Nigeria' as being intrinsically motivated. Roughly a third of officials state that they entered the civil service to serve Nigeria. For each organization, we then construct the fraction of intrinsically motivated bureaucrats. ${ }^{21}$

Column 4 shows how the impact of CS-incentives/monitoring varies by the intrinsic motivation of bureaucrats. The previously documented negative impact of such practices is significantly offset when a greater share of bureaucrats are themselves intrinsically motivated. This runs counter to the notion that incentive provision crowds out efforts of intrinsically motivated individuals: if anything, as in Ashraf et al. [2014], our evidence suggests incentives/monitoring crowd-in the effort of intrinsically motivated bureaucrats. If our CS-incentives/monitoring measure captures SPE being in place for bureaucrats, the result further highlights that intrinsically motivated bureaucrats exert more productive efforts in organizations where such SPE are utilized to a greater extent, rather than engaging in influence activities, say. ${ }^{22}$

\subsubsection{Corruption}

While the recent economics literature has emphasized the importance of the intrinsic motivation of bureaucrats, a long-standing literature in public administration emphasizes that civil servants might pursue their own self-interest [Wilson 1989]. This more negative view of bureaucrats spurs our final set of results, that explore how the impacts of incentives/monitoring are mediated through perceptions of corruption among civil service organizations. Corruption in public bureaucracies is a first order issue in Nigeria, and in many countries at similar stages of development (although the fact that $31 \%$ of projects are completed fully also suggests corruption is not all pervasive).

To elicit information on perceptions of corruption, we began by discussing vignettes with bureaucrats, then made those scenarios closer to the bureaucrat's actual situation, and finally asked individuals about their own observations and experiences of corruption. We asked on what proportion of recent projects the official had worked on, did they observe 'others breaking service

\footnotetext{
${ }^{21}$ In the public administration literature, public service motivation is usually measured using the scale developed in Perry [1996], based on statements related to politics, public service and pro-social activities. This is the approach also followed in Dal Bo et al. [2013]. Alternative approaches employed in the economics literature include: (i) dictator games to examine how many resources an individual transfers to a pro-social task [Ashraf et al. 2014]; (ii) charitable contributions [Buurman et al. 2012]. In our civil servant survey, 'the chance to serve Nigeria' was the modal answer given. The other two most frequent reasons were 'I was interested in the type of work' and 'the stable career path that a job in the service affords', that were each given by around $20 \%$ of individuals

${ }^{22}$ We have explored whether there are within-sample values of the interactions at which the marginal impact of CS-performance is positive. Generally, this is not the case: even for the least complex projects or the most IT advanced organizations the marginal impact of management practices related to incentives/monitoring is negative. For completeness we have also explored the heterogeneous impacts of management practices related to autonomy. We place less attention on these findings because theory offers less guidance for such an analysis. In general, the impact of management practices related to autonomy are homogeneous. They do not significantly vary with project complexity, non-modal project types, or bureaucratic tenure We do find the positive impacts of autonomy to be significantly higher when a greater proportion of bureaucrats report being intrinsically motivated. We leave for future research the exploration of such heterogeneous impacts.
} 
rules for their own benefit'. On average, officials stated that on $38 \%$ of projects such observations of corrupt practice had been made, that, by chance, coincides with the proportion of projects with a zero completion rate. We aggregate this to the organization level to construct the proportion of projects bureaucrats report having observed corrupt practices on. ${ }^{23}$

Column 5 shows how the impacts of both dimensions of management practice vary by perceptions of corruption among bureaucrats. To begin with we note the robust negative levels impacts of our corruption measure on project completion rates. This affirms the measure captures some element of civil servant behavior that is deleterious for public service delivery. However, we see that the marginal impacts of granting bureaucrats autonomy does not vary with the prevalence of corrupt behaviors, and similarly, the negative marginal impact of incentives/monitoring also does not significantly vary with perceptions of corruption among bureaucrats. In short, the evidence suggests that corruption has a direct and quantitatively large negative impact on project completion rates, but there are few bureaucrats on the margin of being prevented from behaving corruptly because of incremental changes in management practice. Of course, this finding is specific to this context and is true for the types of relatively small-scale rural infrastructure projects we consider (whose average budget is below $\$ 100,000$ ). The interplay between corruption and management practices for bureaucrats on larger budget projects remains open to study for future research.

\section{Discussion}

We provide among the first evidence on whether the management of bureaucrats matters for public service delivery. We thus lay down a bedrock of evidence that starts to fill an important knowledge gap, linking the management practices the vital middle-tier of civil service bureaucrats are subject to, and public service delivery. We do so in the context of an important developing country, Nigeria, and at a time when a large number of developing countries are engaged in reforming public bureaucracies along the lines of the 'good governance' agenda of the World Bank and United Nations [Goldfinch et al. 2012, Hasnain et al. 2012]. Our results confirm that two dimensions of management practice emphasized by the public administration and economics literatures: autonomy and incentives/monitoring, correlate to the quantity and quality of public services delivered. Our findings provide support to the notion that public agencies might delegate some decision making to bureaucrats [Simon 1983], at least for the types of small-scale rural infrastructure project we mostly consider. We also provide evidence consistent with two interpretations of why management practices related to incentives/monitoring have detrimental impacts in this setting: bureaucrats operate in a multi-tasking environment, and these management practices pick up elements of $s u b$ -

\footnotetext{
${ }^{23}$ We also asked whether officials had themselves been put under pressure to: (i) change the project location; (ii) change project specifications; (iii) help select particular contractors/suppliers/consultants; (iv) divert some of the funds. Aggregating responses into an organizational average, officials stated that they had experienced such pressures on $19 \%$ of projects. We prefer to use the measure related to observed corrupt practices over this measure because officials are obviously cautious when potentially incriminating themselves.
} 
jective performance evaluation, that lead to other dysfunctional responses among bureaucrats. As such, our results sound a word of caution to the good governance agenda: the simple import of incentive/monitoring practices from the private sector might backfire in bureaucratic settings.

An obvious next step is for researchers to implement field experiments that manipulate practices along both dimensions. While there is a rich body of literature in economics examining the design of incentives and use of monitoring technologies to build on, there remains much scope for thinking through precisely how autonomy/decision rights within organizations can be reallocated. A wider challenge for future experiments aiming to exogenously vary the autonomy of bureaucrats is that if individuals have a lure for authority [Fehr et al. 2013], then the reallocation of power such changes to autonomy necessarily imply, will naturally lead to some constituencies of bureaucrats having incentives to internally block or undermine such changes in management practice, as found in Banerjee et al. [2014].

We conclude by discussing three issues: (i) optimal management practices in bureaucracies; (ii) methodological issues surrounding measuring management practices in bureaucracies; (iii) the interplay between management practices and other mechanisms to improve public service delivery.

\subsection{Optimal Management Practices}

Our results naturally beg the question of why civil service organizations are not optimizing over management practices to begin with. In our context, a fundamental source of this inefficiency arises from organizations being tasked to implement many different types of project (Table 2). As Figure 1 highlights, project types have very different characteristics and so it is unlikely that there exists a unique set of optimal management practices any organization could have in place. This lack of task specialization within civil service organizations is an underlying reason why management practices still matter on the margin. ${ }^{24}$

As discussed by BVR for private sector firms, suboptimal management practices might also persist in equilibrium because: (i) there exist large fixed costs of adopting better practices; (ii) best management practices might be heterogeneous across organizations. While little can be said on the first point using the available data without making strong assumptions, the second point is addressed by our results on the heterogeneous impacts of management practices. Those results imply the optimal incentives/monitoring practices in place should reflect the complexity and ambiguity of projects in an organization's portfolio, the use of IT facilities, as well as the tenure and intrinsic motivation of its bureaucrats. However, these issues were not at the fore during the semi-structured interviews we conducted at organizations to understand what drives

\footnotetext{
${ }^{24}$ In line with this, we find evidence that the detrimental impacts of incentives/monitoring management practices are even more negative for non-modal project types assigned to organizations (the magnitude of the impact being around $40 \%$ of that on modal project-types). This suggests management practices related to performance are better tailored to the modal project type each organization is engaged in. Similarly, we also find that in organizations with a wider portfolio of project types, the negative impact of incentives/monitoring is exacerbated. This again suggests incentives are harder to design in such organizations.
} 
management practices in reality. These all highlighted how practices evolve slowly over time as a function of ground rules laid out in the Public Service Rules of the Nigerian civil service, the history of senior management staff, and trade union demands. As further discussed in BVR, inefficient management practices might also persist for dynamic reasons: learning and adjustment costs might cause best practice to diffuse over time. This is in line with the evidence discussed throughout on the frictions in the labor market for bureaucrats, limiting their mobility across organizations. Finally, a particularly acute concern is that a lack of competitive pressure enables poorly managed public sector organizations to survive. This might especially be true in developing country contexts where mechanisms are rarely in place to allow citizens to choose across alternative public providers of a given good or service, an issue we return to below. ${ }^{25}$

An alternative explanation why bureaucracies do not appear to optimize management practices is based on a Weberian view: organizations do optimize management practices according to their true objective; our evidence merely suggests this objective is weakly aligned with maximizing project completion rates. ${ }^{26}$ To investigate this, we use data from our civil servant survey to check whether management practices correlate to the frequency with which bureaucrats report engaging with politicians and community groups. More precisely, we asked bureaucrats the proportion of projects they engaged with politicians from the National Assembly, with politicians from the State Parliament, with chairmen of local government, and with community/religious groups. With the unit of observation being each bureaucrat's report, we estimate whether this correlates with the CS- measures, conditional on bureaucrat and organization characteristics, and bureaucratic-grade fixed effects. We run each specification separately for manager and non-manager bureaucrats (managers are those at or above grade 12).

Table 7 presents the results, showing that: (i) management practices related to autonomy have weak impacts on bureaucratic engagements with politicians/other groups; (ii) management practices related to incentives/monitoring lead to significantly more engagement with national and state politicians, local government chairman, and community/religious groups; (iii) this second effect exists only for sufficiently high bureaucratic grades (managers). The results might indicate incentives/monitoring practices skew senior bureaucrat's effort away from activities that lead to project completion towards engagement with politicians, in line with the earlier interpretation of incentives being poorly tailored in this setting. Alternatively, if engagement with politicians enables project completion rates to rise, all else equal, the results would imply incentives/monitoring practices are well designed in this context after all. However, the fact that providing bureaucrats

\footnotetext{
${ }^{25}$ In the private sector, Bloom et al. [2012a] provide evidence that product market competition drives innovations towards more better management practices. Bloom et al. [2014] find evidence that hospitals that face competition for patients from rival hospitals do indeed adopt better management practices.

${ }^{26}$ To further assess the degree of alignment in organizational objectives with project completion rates, we regressed the $\log$ of project budgets on each of the 16 subcomponents of the project complexity indicator, as shown in Table A3. The residuals from this regression, that might capture the rents to be gained from the project if it is completed, are found to be weakly positively correlated with actual project completion rates, with a correlation of .13.
} 
more autonomy does not lead them to engage more with politicians leans towards the first interpretation. Collecting more detailed time use data for bureaucrats remains an important avenue for future research. ${ }^{27}$

\subsection{Methodological Issues}

We add to a nascent literature utilizing the BVR approach to measure management practices outside of the private sector. ${ }^{28}$ We fully recognize the scope for future work to investigate the precise dimensions of management practice most relevant in bureaucracies, and design questions that can best help to build indices of these measures. Perhaps part of the issues will become more settled as further work is conducted to understand whether management is best thought of as a technology and input into the production process [Bloom et al. 2014] so that some practices can be thought of as inherently good or bad, or whether it is a form of organizational design where differences in practices are styles optimized by each organization [Gibbons and Roberts 2013].

Moreover, future work on the study of bureaucracies needs to integrate in an analysis of political factors - such as measuring the 'political will' to complete specific projects, identifying informal incentives politicians provide bureaucrats (say through patronage), and better understanding the conflict politicians face in providing bureaucrats autonomy versus their desire to retain political control of public service delivery. All such factors likely interplay with the management practices bureaucrats operate under. Rogger [2014] takes a first step in this direction, using the OPEN data to investigate the extent to which political interference in the bureaucracy explains the productivity of bureaucratic organizations. He finds that while political interference is certainly an important feature of the Nigerian civil service, it is unrelated to management practices: rather it is driven by the political competition politicians face.

\subsection{Other Mechanisms To Improve Public Sector Delivery}

Our analysis fits within a broader literature examining ways to improve public service delivery in developing countries. This highlights mechanisms that can interplay with management practices for bureaucrats within organizations. The first mechanism relates to the selection of bureaucrats into the civil service. Our findings highlight there can be an interplay between the intrinsic motivation of bureaucrats and how they respond to management practices. On turnover, bureaucratic tenure is important both because longer serving bureaucrats shape the management practices in place, but they might also react differently to any given set of incentives, as highlighted in Table

\footnotetext{
${ }^{27}$ Bureaucrats report engaging with national politicians on $12 \%$ of projects. The corresponding figures for the other groups are $7 \%$ for state politicians, $13 \%$ for local government chairmen and $24 \%$ with community groups.

${ }^{28}$ For example, Bloom et al. [2014] study management practices in UK hospitals. In education, MCormack et al. [2013] have measured management practices in nearly 250 departments from 112 UK universities, and Di Liberto et al. [2013] measure management practices in schools in six industrialized countries (they extend BVR to also cover practices related to leadership).
} 
6. A recent contribution in this direction is Dal Bo et al. [2013] who present evidence from Mexico and exploit experimental variation in salaries to identify their impact on the selection of public sector officials. They find higher wages attracted more able workers, and there are no adverse selection impacts in terms of intrinsic motivation. This evidence complements our findings on the impact of management practices once bureaucrats are hired.

The second mechanism is the role of grass roots monitoring of public service providers, the effect of which likely also interplays with management practices in place [Olken 2007]. Along similar lines, Besley and Burgess [2002] and Ferraz and Finan [2008] have documented the significant role that top-down media scrutiny can play for public service provision.

The contours of a rich future agenda for understanding public service delivery (in rich and poor countries) are thus beginning to emerge, linking management practices for bureaucrats, selection/retention policies for bureaucrats, and mechanisms/incentives for the public and politicians to hold public sector organizations accountable. Our contribution is to open the black box of the economic forces driving the behavior of the vital middle-tier of civil service bureaucrats (as distinct from politicians and frontline workers that the literature has previously studied). We hope our analysis spurs methodological advancements in how to measure management practices in bureaucracies, and encourages researchers to design interventions where such practices are experimentally manipulated, as well as other features of bureaucrats' work environment.

\section{A Appendix}

\section{A.1 Measuring Project Complexity}

Data on the complexity of government projects is not directly part of the OPEN data set. We thus worked with a pair of Nigerian engineers familiar with the OPEN projects and a number of international researchers working on technical complexity to define a relevant set of indicators based on the technical documents for each OPEN project. We followed the perspectives on complexity suggested by Remington and Pollack [2007], by asking the engineer-assessors to individually assess projects along the following five topics, each with their own set of indicators.

Structural complexity stems from the scale of different interconnected tasks and activities. The indicators associated with this topic capture structural aspects such as project size and the number of inputs required for production. They also capture issues in raw material and labour supply, and the ease with which any necessary specialized skills and equipment can be sourced. Temporally complex projects are those whose production involves uncertainties. Hence there are indicators

for uncertainties in design and implementation. Technically complex projects are those whose production have ambiguous risks, namely their uncertainties are not well understood. Hence some indicators capture ambiguities in design and implementation. Directional complexity refers to the potential for preferences over the project to diverge. The engineer assessors are thus asked to 
rate the managerial complexities of the project. Finally, there is a subjective assessment as to the overall complexity of the project. This allows any unassessed aspects of complexity to be measured and provides a comprehensive picture of project complexity.

Two qualified and independent Nigerian engineers were then contracted to assess each project in the OPEN data set along these margins. The process of aggregation between engineers used in this project aimed to build a consensus. The first engineer coded indicators for the entire data set. The codings of the first engineer were then provided to the second engineer who then constructed his own codings with reference to the codings of the first. The aim was to anchor the coding of the second engineer in that of the first but give him freedom to disagree where he felt the coding was incorrect. We decided this approach balanced consensus and subjectivity.

The two engineers were provided with project details and documents and asked to code a value for each indicator. The documents only contained information available before implementation such that there was no bias from the coding being done after the projects were implemented.

Table A3 provides descriptive statistics for all 16 indicators from which the complexity index is constructed, as well as how each is correlated with the other indicators. Aggregate complexity is a subjective assessment of the overall complexity of the projects by the two engineers, that includes 'all factors that might influence the difficulty of implementing the project, not only those assessed [by the other indicators]'. We asked the engineers to take the distribution of complexity in the OPEN data set as a whole, with the least complex project in the data having an aggregate complexity of zero and the most complex project having an aggregate complexity of 100, and place each project within this distribution.

We undertook a number of measures to check the complexity of the OPEN indicators coded by the engineers. First, we inserted 200 randomly chosen repeated projects into the data set provided to the engineers. Since the project characteristics of the original and repeat projects are identical, we would expect that the codings of the two sets of projects would be similar. Reassuringly, we find that in general the original and duplicate projects are coded in similar ways. We compare the differences between these two sets by looking at group and paired means, and distributional tests for each variable. The differences are only statistically significant at conventional levels in a few cases, and the magnitude of the differences are relatively small. For example, the only variable that is statistically significantly different below the $10 \%$ level in the mean-comparison t-test relates to raw material storage. Here, despite a standard deviation of .2 in the originals, the difference is .07 between the originals and the duplicates. Second, we looked at the similarity of the codings of the two engineers. We find that the second engineer's codings are not dramatically different from the first engineer's efforts. Whilst there are a small number of differences, they are relatively small and rarely significant, indicating that the re-coding left the overall picture relatively stable. Finally, over a year after he had completed the prompted codings, we asked the second engineer to re-code a sub-sample of projects from scratch, this time without prompting. The differences between these independent codings and the consensus data we rely on are again relatively minor. 
It seems that once he had become accustomed to the broad parameters of the coding framework, the second engineer's coding was not dissimilar to the consensus generated by the two engineers working one after the other.

We therefore have evidence of similar projects within the data set being coded in a similar way, of the two engineers coding in similar ways both when prompted and unprompted, and when there were deviations, of the deviations not being particularly quantitatively large. Taken together these checks reassure us that the complexity measures pick up meaningful variation across projects.

\section{A.2 Standard Errors}

Our baseline specification assumes the disturbance term is clustered by project type-organization. Table A5 shows the robustness of our results to alternative assumptions on the error structure. The table is structured to cover the same specifications as in Columns 1 to 4 of Table 4, but where we now report standard errors based on alternative assumptions: (i) robust standard errors; (ii) errors clustered by project-type and organization as in Table 4; (iii) standard errors clustered by organization. One concern with such clustered standard errors is that they may be downwards biased when the number of clusters is small (and in our specification the number of clusters corresponds to 63) [Cameron et al. 2008]. They propose various asymptotic refinements using bootstrap techniques, finding the wild cluster bootstrap-t technique performs particularly well in Monte Carlo simulations. We have implemented this method on our baseline specifications and show in brackets in Columns 1 to 4 the resulting p-values. This correction does not alter the significance of any of the coefficients from our preferred specification with project type fixed effects shown in Column 4 of Table A5.

\section{A.3 Robustness Checks}

We conduct a wide range of robustness checks on our core result on project completion rates. To begin with we note that the results in Table 4 used our continuous measure of project completion rates (from zero to one) as the dependent variable. However, an alternative approach is to define a threshold of completion that would deem the project usable. To do so we consider all potential thresholds from $1 \%$ to $100 \%$ in increments of $1 \%$ and then estimate a specification analogous to (1) where $y_{i j n}$ is defined as a dummy variable equal to one if the project completion rate is above the given threshold $p \%$, and zero otherwise. For any given threshold $p$ the coefficients of interest are denoted $\gamma_{1 p}$ and $\gamma_{2 p}$. Figure A1 then plots each pair of $\left(\widehat{\gamma}_{1 p}, \widehat{\gamma}_{2 p}\right)$ estimates, for each threshold and their associated $95 \%$ confidence interval.

Two points are of note. First, at the extreme left of the figure where we consider a $1 \%$ threshold, we are essentially using a linear probability model to assess the relationship between management practices in civil service organizations and whether projects are started in some way. 
This essentially replicates the extensive margin specification shown in Column 5 of Table 4. Here we find marginal impacts of each type of management practice to be qualitatively similar to those documented earlier for the average completion rate, although the point estimate on CS-autonomy seems to be lower than the baseline specification. ${ }^{29}$ Second, we cannot reject the null that the sign and significance of the coefficients are the same for every threshold of project completion. Taken together, the results imply that managerial incentives along both margins have similar impacts on the extensive margin of public service delivery (namely whether projects are started at all) and the total effect margin of project completion (namely a weighted average of the project being started, and the extent to which projects are completed conditional on being started).

The checks detailed in Table A7 all verify the robustness of our main finding to alterative samples of organizations and projects: Column 1 excludes those projects implemented by the largest organization in terms of total expenditures. Column 2 excludes projects implemented by the largest organization in terms of number of projects. Columns 3 and 4 remove the 10 smallest organizations by expenditures and number of projects respectively. Columns 5 and 6 exclude organizations at the top and bottom of the CS-autonomy and CS-incentives management scales respectively. In each cut of the data, the core results remain stable, so that our findings do not appear to be drive by outlier or specific organizations.

The third series of robustness checks in all probe the core results in alternative subsamples of data (with the caveat that such splits of the data inevitably lead to less precise estimates). Columns 7 and 8 in Table A7 break down the project types listed in Table 1 into two groups: those related to construction projects (borehole, building, electrification, dam, road and canal) and those related to non-construction projects. We find that for construction projects, the results closely replicate the baseline findings. Indeed, for construction projects as a whole the point estimates on each management practice index is slightly larger in absolute value than the baseline result in Column 4 of Table 4. For non-construction projects, the results show that CS- autonomy continues to have a positive and significant impact on project completion rates; CS-incentives has a negative correlation with project completion rates that is significant at the $10 \%$ level. As suggested by Figure 1, this might be because non-construction projects such as training and procurement, are inherently less ambiguous in design.

The next split considered in Columns 9 and 10 is between centralized and decentralized civil service organizations, where centralized agencies correspond to government ministries. We see the impacts of CS-autonomy to be similar in both, although the CS-index index only has negative impacts in the centralized agencies. This latter result is worth exploring in future work.

The next robustness check addresses the concern that different management practices might be

\footnotetext{
${ }^{29}$ There is not continuous mass in project completion rates over the $[0,1]$ interval: hence we do not expect the marginal impact of the each management practice to be sensitive to marginal changes in threshold $p$ where there is little mass in project completion rates. This explains why the marginal impacts shown in Figure A1 jump at a small number of points.
} 
spread across the country in a way that is correlated with characteristics of the organization's local geographies. Indeed, it is well understood that the characteristics of local populations interplay with them being able to solve collective action problems, and thus are an important driver of public goods provision [Banerjee et al. 2007]. To address this issue, Column 11 additionally controls for a wide variety of state-level controls for each project and finds almost no change in the coefficients of interest. In short, local area characteristics do not seem to be driving our results. ${ }^{30}$ Columns 12 and 13 split the sample into projects that are located in the Northern and Southern regions of Nigeria respectively, that characterizes the first order cultural divide in Nigeria, and provides a relatively even split in the number of projects. We find the impacts of both management practices to remain significant in both regions. This suggests that cultural differences across regions do not much interact with responses to these management practices.

The final two robustness checks relate to methodological issues. First, we consider alternative constructions of the CS- management practice indices. As described in Section 3.3, following BVR, we aggregated responses to individual questions to construct our indices of management practices giving equal weight to all questions. A natural alternative is to cluster the variables into the various management topics described in Table A4 and weight each topic (rather than each variable) equally. We re-construct our CS-autonomy and CS-incentives measures along these lines and re-estimate our preferred specification (1). The result, in Column 14 of Table A7 is qualitatively in line with our baseline results, although the absolute magnitude of each measure of public sector management is larger: a one standard deviation increase in CS-autonomy corresponds to a significantly higher project completion rate of $23 \%$, and a one standard deviation increase in CS-incentives corresponds to a significantly lower project completion rate of $14 \%$.

The analysis has so far estimated (1) using OLS. The final robustness check estimates this specification using a fractional regression model that accounts for the dependent variable being a continuous variable between zero and one. To do so, we utilize Papke and Wooldridge's [1996] fractional logit model in which the conditional expectation function is modelled as a logistic function that can take all values in the unit interval. The interpretation of the marginal effects are the same as in the binary logit model and evaluated at sample averages, the partial effects are approximately comparable to the coefficients from a linear regression. The result in Column 15 of Table A7 shows our core findings to be robust to this alternative estimation model.

\section{A.4 Alternative Groupings of Management Practice}

We clearly recognize there is no definitive way to collate management practices into aggregate indices of autonomy and incentives/monitoring. Table A8 explores alternative ways to construct both indices. On the autonomy measure, to reflect that the capabilities of bureaucrats are crucial

\footnotetext{
${ }^{30}$ We construct these state controls using aggregated data provided by the National Bureau of Statistics. The sample drops slightly in this specification because the state in which the project is located (or should have been located for those projects that are never started) is missing for around 450 projects.
} 
to how much autonomy they have, we aggregate a new autonomy measure from the subcomponents shown in Table A4 related to "roles" and "skills". The result, in Column 2 of Table A8, shows this measure of autonomy to have a positive and significant effect on project completion rates, although the point estimate is smaller than our preferred measure. We next consider an alternative incentives/monitoring measure that also encompasses the use of "targets" in the organization: this new measure reflects the creation of goals for the organization that officials are required to move towards. Column 3 of Table A8 shows this measure of incentives/monitoring to have negative and significant effects on project completion rates. An alternative way to group the practices related to incentive provision is if they relate to output based incentives, input based incentives or a combination of both (as shown in Table A4). The result in Column 4 of Table A8, shows each aspect of incentives to have negative and significant effects on project completion rates.

\section{A.5 Decomposing Management Practices}

We elicited management practices along nine dimensions in each organization: roles, flexibility, incentives, monitoring, culture, targeting, facilities, skills and staffing. We now estimate a specification analogous to (1) but where we condition on the nine separate dimensions of management practice. This disaggregated specification serves two purposes: (i) by breaking up the CS-other measure into its components, it helps assess if there are other aspects of management practice that the CS-autonomy and CS-incentives measures might be picking up; (ii) it underpins the validity of the three-way classification of management practices in our baseline specification.

Table A9 first estimates the impact of each dimension separately. The roles and flexibility subcomponents that formed our CS-autonomy measure are individually positive and significantly different from zero (Columns 1 and 2). Columns 3 and 4 show that each subcomponent that formed the CS-incentives index is negatively and significantly related to project completion rates. Columns 5 to 9 then split the remaining management practices that were previously within the CS-other measure. Most of these have no significant impact on project completion rates.

In Column 10 we simultaneously control for all nine CS- components, and find: (i) both roles and flexibility components remain positive and individually significantly correlated to project completion rates; (ii) the incentives component is negative but not significantly different from zero (the point estimate hardly changes from Column 3 but the standard error almost doubles), while the monitoring component remains negative and significantly correlated with project completion rates; (iii) four out of five of the other dimensions of management practice remain insignificant.

The fact that different elements of management practice have positive, zero, or negative impacts on project completion rates helps allay the concern that the CS- measures used in our core results simply pick up some unobserved element of management practice. If organizations that employed the most resourceful and skilled bureaucrats were also those best able to provide autonomy to their bureaucrats and adapt to new scenarios, then we would be concerned that the partial 
correlation between CS-autonomy and project completion rates was being partly confounded by

such other factors. That other dimensions of management practice related to culture or staffing are uncorrelated with project completion rates, suggests this is not the case.

In Column 11 we aggregate all nine indices into a single management index, as considered by BVR for manufacturing firms. In our setting such aggregation leads to the wrong conclusions being drawn: we find no significant relationship between the aggregate CS-management measure and project completion rates. The reason is clear: the underlying components of the aggregate index do not all have the same signed impacts on project completion rates. Hence management of bureaucrats does matter, but different dimensions of management practice have very different impacts on outcomes in this public sector setting.

\section{B Econometric Concerns}

Absent exogenous variation in management practices, we have interpreted our findings as partial correlations between the CS- measures and public service delivery. To assess the extent to which these findings can map to a causal interpretation of the impacts of the CS- measures, we provide evidence on the likely severity of two econometric concerns: (i) projects being non-randomly assigned to organizations based on their management practices; (ii) unobservables correlated to management practices and also drive project completion rates.

\section{B.1 Project Assignment}

The first class of concerns relate to the assignment of projects to organizations on the basis of management practices. For example, if better managed organizations are more likely to be assigned harder-to-implement projects, this creates a spurious negative correlation between our CS- measures and project completion rates. This suggests $\left(\widehat{\gamma}_{1}, \widehat{\gamma}_{2}\right)$ are both biased in the same direction, and hence a more complicated explanation is required to imply that $\widehat{\gamma}_{1}$ is both upwards biased and $\widehat{\gamma}_{2}$ is downwards biased. We investigate the potential non-random assignment of projects in two ways.

We first use a conditional logit model to directly estimate the likelihood of project $i$ being assigned to organization $n$ conditional on the management practices for bureaucrats in place in the organization, and other project and organizational characteristics exploited in our analysis. To do so we first reshape our data as follows: for each project we created a binary variable with 63 values corresponding to our 63 organizations. The variable, denoted $D_{i n}$, takes the value one for the organization at which that project is actually assigned, and zero otherwise. Thus, the data-set is at the project-organization pair level $(\mathrm{in})$, with a total of $4721 \times 63=297,423$ project-organization paired observations. To each observation, we attach the relevant organization-level characteristics used in our analysis (that were denoted $O C_{n}$ in (1)), such as our management indices, capital 
controls and organizational averages of bureaucrat characteristics. We then also consider whether specific project-organization interactions, denoted $Z_{i n}$, correlate with the assignment of projects to organizations. We estimate a conditional logit specification for $\operatorname{Prob}\left(D_{\text {in }}=1\right)$, based on both sets of characteristics;

$$
\operatorname{prob}\left[D_{i n}=1\right]=\frac{\exp \left(\beta^{\prime} O C_{n}+\gamma^{\prime} Z_{i n}\right)}{\sum_{n} \exp \left(\beta^{\prime} O C_{n}+\gamma^{\prime} Z_{i n}\right)} .
$$

Note that in this modelling framework project characteristics play no role as these do not vary within a given project $i$ over the organizations $n$ it could potentially have been assigned to.

We run three sets of specifications. The first takes the perspective that each project could have been assigned to any of our 63 organizations. The second takes the perspective that projects can only be implemented by organizations of the same sector. Thus, health projects could only be implemented by health sector organizations for example. When we impose this restriction on the permissible project-organization pairs, we lose 847 projects as there is only one organization of that sector in our data, and there are 44,429 potential within sector project-organization pairs. The third specification further imposes the assumption that projects can only potentially be assigned to organizations in the same sector that are observed being tasked to implement a project of the same complexity. This further reduces the sample to 33, 480 feasible project-organization pairs. In all specifications we cluster standard errors by organization as there are likely to be unobserved characteristics of organizations that determine project assignments.

Table A10 presents the results. Column 1 utilizes the entire set of project-organization combinations and uses only our management scores in the regression. Unconditional on other organization characteristics, neither management practice related to autonomy or performance-based incentives significantly predicts the assignment of projects to organizations. When we restrict the sample so that each project can only feasibly be assigned to organizations in the same sector, Column 2 shows the coefficient on CS-autonomy to become significant at the $10 \%$ level, but this result is not robust. In Column 3 where we restrict the feasible pairs also using information on the complexity of projects, we find the probability of projects being assigned to organizations do not significantly correlate with the management practices in place in the organization.

Column 4 extends the specification to include all the organizational controls utilized in our baseline specification (capital, general and noise), as well as the full set of organizational controls that we use elsewhere in the paper. The coefficients on the management practices remain insignificantly different from zero at the usual levels. Moreover, we find no evidence that any of these other organizational characteristics predict the assignment of a given project to that particular organization rather than other organizations it could feasibly have been assigned to.

In Column 5 we additionally control for a series of interactions between project characteristics (scale, complexity) and organizational characteristics (total staff, total budget). Some of these project-organization interactions do predict the assignment of projects. As is intuitive, we find 
that the interactions between the number of staff at an organization and the project budget, and the organization's total budget and the project complexity, both are positive and significant predictors of project assignment. Over and above these interactions, we continue to find no impact of management practices on project assignment even once we allow for specific matched pairs to be assigned in this way.

Overall, these results suggest our results are not reflecting the non-random selection of projects to organizations based on their management practices. While there is no doubt some complex bargaining process between Parliament, civil service organizations and other stakeholders that determined the assignment of projects to locations and organizations, on the margin, this assignment is uncorrelated with the management practices in place in implementing organizations.

Our second approach conducts further analysis at the organization level, estimating the following specification,

$$
w_{n}=\theta_{1} C S \text {-autonomy } y_{n}+\theta_{2} C S \text {-incentives }{ }_{n}+\theta_{3} C S \text {-other }{ }_{n}+\pi X_{n}+\epsilon_{n}
$$

where observations are for the 63 organizations listed in Table A1, $w_{n}$ are measures related to the set of projects assigned to organization $n$ by Parliament, the CS- measures are as previously described, and $X_{n}$ includes the same organization level controls and noise controls as previously described. Robust standard errors are reported. The results are presented in Table A11 and show that: (i) $\widehat{\theta}_{1}$ and $\widehat{\theta}_{2}$ are both positive, so that organizations that provide more autonomy and performance incentives to bureaucrats are assigned more projects, but neither correlation is significantly different from zero (Column 1); (ii) the unique number of project types assigned to an organization is also not significantly related to the management practices in place (Column 2). Taken together, these results suggest that whatever the bargaining game between stakeholders in the Parliamentary procedure that assigns projects to organizations, there is not much to suggest it is based on management practices in those organizations.

\section{B.2 Unobservables}

The second class of concern is that our measures of management practice are correlated to unobserved factors in $\epsilon_{i j n}$, and these unobservables directly determine project completion rates thus biasing our coefficients of interest. Unobserved factors might relate to features of organizations or bureaucrats.

\section{B.2.1 Organization Features}

Table A11 addresses this concern by using specification (1) to check whether management practices correlate to other organizational outcomes beyond project completion rates. In Column 3 we construct the average complexity of projects assigned to organization $n$ as our dependent 
variable, and then regress this against our measures of management practice and other organizational characteristics. Neither CS- measure is significantly correlated to the average complexity of projects the organization is tasked to implement. Hence it is not the case that organizations with better practices related to autonomy are assigned easier projects, and those with more incentives/monitoring are assigned harder to implement projects. In Column 4 we use the log of the organization's aggregate budget as our dependent variable: again we find no correlation between the management practices in place and the organization's resources. Hence it is not the case that organizations that have better practices also command larger budgets overall, that might otherwise have indicated it was easier for the organization to complete their assigned projects.

\section{B.2.2 Bureaucrat Characteristics}

If bureaucrats sort into organizations based on management practices, then the impacts of such practices are confounded by any direct relation between bureaucrat characteristics and project delivery. In Section 2 we highlighted there are frictions in the labor market for bureaucrats that limit the scope for individuals to freely join or move across organizations, and hence this also limits the ability of organizations to use management practices to attract certain types of bureaucrat. Table A12 presents additional characteristics of bureaucrats elicited in our civil servant survey to shed light on this issue, aggregating each response to an organizational average. Column 1 shows the mean and standard deviation of the bureaucrat characteristic for the average organization.

Columns 2 and 3 show regression coefficients $\left(\widehat{\theta}_{1}, \widehat{\theta}_{2}\right)$ from a specification analogous to $(3)$, where the dependent variable is the organizational average for the bureaucrat characteristic and we condition on the organizational characteristics in $O C_{n}$. Robust standard errors are in parentheses.

The first batch of characteristics investigate the specific social connections bureaucrats have with senior staff in the organization to which they are appointed: almost no bureaucrats report knowing their direct boss, or other managers, prior to their appointment. The lack of variation in this response precludes it being regressed against the CS- practices. Where there is more variation is in terms of the number of close colleagues that were known to the individual prior to their assignment: on average, bureaucrats report knowing 4.40 other colleagues. However, we find this degree of linkage across bureaucrats, when averaged to the organization level, to be uncorrelated with the management practices in place related to autonomy and performance incentives. Our next question elicits information on personal connections among bureaucrats by asking individuals whether they were the first family member to join the civil service: $48 \%$ of bureaucrats in the average organization report being the first in their family. We find no correlation between this measure of bureaucrat networks and the management practices in place.

We next consider additional bureaucrat characteristics that might be indicative of the 'reliability' of bureaucrats, and examine whether such measures correlate to the management practices in place. Throughout, we split bureaucrat characteristics into those of senior and low-tier bu- 
reaucrats, as these different tiers might differentially impact the management practices in place. As shown in the lower half of Table A12, we find no significant correlation between management practices related to autonomy or performance incentives and the average tenure of bureaucrats, the proportions of them that report being intrinsically motivated, or that report observing corrupt practices on projects (for both senior and lower-tier bureaucrat characteristics). ${ }^{31}$

A second approach to measuring bureaucrat 'reliability' is based on responses to vignettes on scenarios bureaucrats face. One vignette relates to the following situation: an official in an organization like theirs is told by her manager to take funds from a certified project and give them to a contractor/supplier for projects that the government has yet to complete due process on, against public service rules. The contractor then does not do the work he was paid for. We asked bureaucrats whether they agreed/disagreed with various statements related to the vignette: whether the bureaucrat acted correctly, whether the bureaucrat's manager acted correctly, whether bureaucrats should sometimes go against rules and so forth. We find little evidence of any significant relationship between the proportion of bureaucrats that agree with each such statement and the management practices in place in the organization. If such vignettes are informative of bureaucrat 'types', this evidence suggests that typically harder to observe measures of bureaucrat reliability are not much correlated with management practices in place. $^{32}$

\section{References}

[1] ACemoglu.d (2005) "Politics and Economics in Weak and Strong States", Journal of Monetary Economics 52: 1199-226.

[2] ACEmoglu.D, P.Aghion, C.Lelarge And F.ZIlibotti (2007) "Technology, Information and the Decentralization of the Firm", Quarterly Journal of Economics 122: 1759-99.

[3] AGhion.P And J.TiRole (1997) "Real and Formal Authority in Organizations," Journal of Political Economy 105: 1-29.

\footnotetext{
${ }^{31}$ These results suggest that it is not the case that organizations limit the provision of performance-based incentives to attract intrinsically motivated workers [Delfgaauw and Dur 2010], or that the matching of intrinsically motivated workers to public sector organizations limits the need to use performance-based incentives [Besley and Ghatak 2005]. Both findings are partly driven by the rigidities in the assignment of bureaucrats to organizations.

${ }^{32}$ Enumerators stressed there were no right answers, and vignettes were phrased in reference to a bureaucrat in the third person (Ngozi). Officials were asked whether they agreed or disagreed with the following statements: (i) 'Ngozi should have refused to divert the funds and paid the contractors/suppliers/consultant for the certified project' (76\% agreed); (ii) 'The contractors/suppliers/consultant should not have accepted the funds given that Due Process had not been followed' (68\%); (iii) 'The boss was wrong to direct Ngozi to share the funds of a project with others' (81\%); (iv) 'Sometimes it is right to go against strict rules, as Ngozi did, so to make things fairer or more efficient' (28\%); (v) 'Bureaucrats should be given more space to interpret what the best action to take in a given situation is' (59\%). We check whether there is a significant correlation between the proportion of bureaucrats that agree with each statement and the management practices in place: nine out of ten correlations are insignificant.
} 
[4] Alabi.m.o.A And J.Y.fashagba (2010) "The Legislature and Anti-corruption Crusade under the Fourth Republic of Nigeria: Constitutional Imperatives and Practical Realities," International Journal of Politics and Good Governance 1.

[5] AShraf.n, O.BAndiera And K.JACK (2014) "No Margin, No Mission? A Field Experiment on Incentives for Pro-social Tasks," Journal of Public Economics 120: 1-17.

[6] BAKER.G.P (2002) "Distortion and Risk in Optimal Incentive Contracts," Journal of Human Resources 37: 728-51.

[7] Bandiera.o, A.Prat And t.valletti (2009) "Active and Passive Waste in Government Spending: Evidence from a Policy Experiment," American Economic Review 99: 1278-308.

[8] Banerjee.A, R.Chattopadhyay, E.duflo, D.Keniston And N.Singh (2014) Improving Police Performance in Rajasthan, India: Experimental Evidence on Incentives, Managerial Autonomy and Training, mimeo, MIT.

[9] Banerjee.A, L.IYer And R.Somanathan (2007) "Public Action for Public Goods," in Handbook of Development Economics Vol. 4, T.P.Schultz and J.Strauss (eds.), Elsevier.

[10] Benabou.r And J.TiRole (2006) "Intrinsic and Extrinsic Motivation," Review of Economic Studies 70: 489-520.

[11] Besley.T (2004) "Paying Politicians: Theory and Evidence," Journal of the European Economic Association 2: 193-215.

[12] Besley.T AND R.BURgess (2002) "The Political Economy of Government Responsiveness: Theory and Evidence from India," Quarterly Journal of Economics 117: 1415-52.

[13] BeSLey.T AND M.GHATAK (2005) "Competition and Incentives with Motivated Agents," American Economic Review 95: 616-36.

[14] Besley.t And t.Persson (2010) "State Capacity, Conflict and Development," Econometrica 78: $1-34$.

[15] BLACK.S AND L.LYNCH (2001) "How to Compete: The Impact of Workplace Practices and Information Technology on Productivity," Review of Economics and Statistics 88: 434-45.

[16] BLOOM.n AND J.VAn REEnen (2007) "Measuring and Explaining Management Practices Across Firms and Countries," Quarterly Journal of Economics 122: 1351-1408.

[17] Bloom.n And J.VAn ReEnen (2010) "New Approaches to Surveying Organizations," American Economic Review 100: 105-9. 
[18] BloOm.n, R.SAdun And J.VAn Reenen (2012a) "The Organization of Firms Across Countries," Quarterly Journal of Economics 127: 1663-1705.

[19] BloOm.n, R.SAdun And J.van REenen (2012b) "Americans do I.T. Better: US Multinationals and the Productivity Miracle," American Economic Review 102: 167-201.

[20] Bloom.n, R.SAdun And J.VAn ReEnen (2014) Management as a Technology, mimeo, LSE.

[21] Bloom.n, B.eifert, A.mahajan, D.mCKenzie And J.Roberts (2013) "Does Management Matter: Evidence from India," Quarterly Journal of Economics 128: 1-51.

[22] Bloom.n, C.Propper, S.SEILER And J.VAn REenen (2014) The Impact of Competition on Management Practices in Public Hospitals, forthcoming, Review of Economic Studies.

[23] Butrman.m, J.DelfgaAuW, R.DuR And s.VAn Den bossche (2012) "Public Sector Employees: Risk Averse and Altruistic?," Journal of Economic Behavior and Organization 83: 279-91.

[24] CAmeron.C, J.Gelbach And D.miller (2008) "Bootstrap-Based Improvements for Inference with Clustered Errors", Review of Economics and Statistics 90: 414-27.

[25] DAL BO.E, F.FinAN AND M.Rossi (2013) "Strengthening State Capabilities: The Role of Financial Incentives in the Call to Public Service," Quarterly Journal of Economics 128: 1169-218.

[26] DelfGaAuW.J And R.Dur (2010) "Managerial Talent, Motivation, and Self-Selection into Public Management," Journal of Public Economics 94: 654-60.

[27] Di Liberto.A, F.SChivardi And G.Sulis (2013) Managerial Practices and Students' Performance, mimeo, LUISS.

[28] DiJkstra.G, B.AKAnji, C.Hiddink, s.sangarabalan And F.DE Mevius (2011) Mutual Interests - Mutual Benefits: Evaluation of the 2005 Debt Relief Agreement Between the Paris Club and Nigeria, Ministry of Foreign Affairs of the Kingdom of the Netherlands.

[29] DixiT.A (2002) "Incentives and Organizations in the Public Sector: An Interpretive Review," Journal of Human Resources 37: 696-727.

[30] Duflo.e, R.HAnna And S.P.RYAn (2012) "Incentives Work: Getting Teachers to Come to School," American Economic Review 102: 1241-78.

[31] Евон.e (2010) MDGs-based Planning in Africa: Lesson, Experiences and Challenges: A Case Study of Nigeria, Addis Ababa: United Nations Economic Commission for Africa. 
[32] Federal Government of nigeria (2007) The Story of OPEN.

[33] federal GOVernment of nigeria (2008) Monitoring and Evaluation Report of the DRGFunded MDG Projects and Programmes in Nigeria 2006.

[34] federal Government of nigeria (2009) Monitoring and Evaluation Report of the DRGFunded MDG Projects and Programmes in Nigeria $200 \%$.

[35] Fehr.e, H.herz And T.Wilkening (2013) "The Lure of Authority: Motivation and Incentive Effects of Power," American Economic Review 103: 1325-59.

[36] FERRAZ.C AND F.FInAN (2008) "Exposing Corrupt Politicians: The Effects of Brazil's Publicly Released Audits on Electoral Outcomes," Quarterly Journal of Economics 123: 703-45.

[37] FlodGRen.G, M.P.ECCLES, S.SHEPPERD, A.SCOTt, E.PARMELli AND F.R.BEYER (2011) "An Overview of Reviews Evaluating the Effectiveness of Financial Incentives in Changing Healthcare Professional Behaviours and Patient Outcomes," Cochrane Database of Systematic Reviews Issue 7, Art. No.: CD009255.

[38] Francois.P And M.vlassopoulos (2008) "Pro-social Motivation and the Delivery of Social Services," CESifo Economic Studies 54: 1-33.

[39] FrYER.R.G (2013) "Teacher Incentives and Student Achievement from New York Public Schools," Journal of Labor Economics 31: 373-407.

[40] Gagliarducci.s And t.nannicini (2013) "Do Better Paid Politicians Perform Better? Disentangling Incentives from Selection," Journal of the European Economic Association 11: $369-98$.

[41] Gibbons.r And J.roberts (2013) The Handbook of Organizational Economics, Princeton: Princeton University Press.

[42] GLewwe.P, N.ILias And M.kremer (2010) "Teacher Incentives," American Economic Journal: Applied Economics 2: 205-27.

[43] Goldfinch.S, K.Derouen And P.Pospieszna (2012) "Flying Blind? Evidence for Good Governance Public Management Reform Agendas, Implementation and Outcomes in Low Income Countries," Public Administration and Development 33: 50-61.

[44] hasnain.Z, N.manning And J.H.Pierskalla (2012) Performance-related Pay in the Public Sector, World Bank Policy Research Working Paper 6043. 
[45] Holmstrom.B And P.milgrom (1991) "Multitask Principal-Agent Analyses: Incentive Contracts, Asset Ownership, and Job Design", Journal of Law, Economics and Organization 7: 24-52.

[46] ichniowski.c, K.SHAW And G.PREnnushi (1993) "Effects of Human Resource Management Practices," American Economic Review 87: 291-313.

[47] Kelman.s (1990) Procurement and Public Management: The Fear of Discretion and the Quality of Public Performance, Washington DC: American Enterprise Initiative.

[48] martinez-Bravo.m (2014) "The Role of Local Officials in New Democracies: Evidence from Indonesia", American Economic Review 104: 1244-87.

[49] mCCormack.J, S.Smith And C.Propper (2013) Herding Cats? Management and University Performance, CMPO Working Paper 13/308.

[50] Milgrom.P.R (1988) "Employment Contracts, Influence Activities, and Efficient Organization Design", Journal of Political Economy 96: 42-60.

[51] Milgrom.P.R AND J.Roberts (1988) "An Economic Approach to Influence in Organizations", American Journal of Sociology 94: S154-79.

[52] Miller.G AND K.S.BABiarz (2013) Pay-For-Performance Incentives in Low- and MiddleIncome Country Health Programs, NBER WP 18932.

[53] muralidharan.K And V.Sundararaman (2011) "Teacher Performance Pay: Experimental Evidence from India," Journal of Political Economy 119: 39-77.

[54] muralidharan.k (2012) Long-Term Effects of Teacher Performance Pay: Experimental Evidence from India, mimeo UCSD.

[55] NKonjo-IWeala.n and P.osafo-KWaAko (2007) Nigeria's Economic Reforms: Progress and Challenges, Brookings Institute Global Working Papers Washington: Brookings Institute.

[56] OLken.B (2007) "Monitoring Corruption: Evidence from a Field Experiment in Indonesia," Journal of Political Economy 115: 200-49.

[57] Ogundiya.I.s (2011) "Anti-corruption Reforms in Nigeria: Challenges and Failures," in I.S.Ogundiya, S.Ilufoye, A.Olanrewaju Olutayo and J.Amzat (eds.) Assessment Of Democratic Trends In Nigeria, Delhi: Gyan Publishing House.

[58] Papke.t.e And J.m.wooldridge (1996) "Econometric Methods for Fractional Response Variables with an Application to 401(k) Plan Participation Rates," Journal of Applied Econometrics 11: 619-32. 
[59] Perry.J.L AND L.R.Wise (1990) "The Motivational Basis of Public Service," Public Administration Review 50: 367-73.

[60] Perry.J.L (1996) "Measuring Public Service Motivation: An Assessment of Construct Reliability and Validity," Journal of Public Administration Research and Theory 6: 5-22.

[61] Perry.J.L, T.A.engers And S.Y.Jun (2009) "Back to the Future? Performance-related Pay, Empirical Research, and the Perils of Persistence," Public Administration Review 69: 39-51.

[62] Prendergast.c (2002) "The Tenuous Trade-Off between Risk and Incentives", Journal of Political Economy 110: 1071-102.

[63] Remington.K And J.Pollack (2007) Tools for Complex Projects, Aldershot: Gower.

[64] Rogger.D (2014) The Causes and Consequences of Political Interference in Bureaucratic Implementation: Evidence from Nigeria, mimeo, UCL.

[65] Rose-ACKerman.s (1986) "Reforming Public Bureaucracy Through Economic Incentives?," Journal of Law, Economics and Organization 2: 131-61.

[66] SCOTt.A, P.Sivey, D.Ait OUAKRIM, L.WILlEnberG, L.NACCARELla, J.FuRleR AND D.YOUNG (2011) "The Effect of Financial Incentives on the Quality of Health Care Provided by Primary Care Physicians," Cochrane Database of Systematic Reviews Issue 9. Art.No.: CD008451.

[67] Simon.w (1983) "Legality, Bureaucracy, and Class in the Welfare System," Yale Law Journal 92: 1198-269.

[68] Tullock.g (1965) The Politics of Bureaucracy, Washington: Public Affairs Press.

[69] Wilson.J (1989) Bureaucracy: What Government Agencies Do and Why They Do It, New York: Basic Books. 
Table 1: Descriptive Evidence on Project Types

\begin{tabular}{|c|c|c|c|c|c|c|c|c|}
\hline Project Type & $\begin{array}{l}\text { (1) Number of } \\
\text { Projects } \\
\text { [Proportion] }\end{array}$ & $\begin{array}{l}\text { (2) Number of } \\
\text { Implementing } \\
\text { Organizations }\end{array}$ & $\begin{array}{l}\text { (3) Median } \\
\text { Budget Allocation } \\
\text { (US } \$ 000 \text { s) }\end{array}$ & $\begin{array}{l}\text { (4) Proportion } \\
\text { Never Started }\end{array}$ & $\begin{array}{l}\text { (5) Average } \\
\text { Completion } \\
\text { Rate }\end{array}$ & $\begin{array}{l}\text { (6) Proportion } \\
\text { Completed } \\
\text { Conditional on } \\
\text { Being Started }\end{array}$ & $\begin{array}{l}\text { (7) Proportion } \\
\text { Fully } \\
\text { Completed }\end{array}$ & $\begin{array}{l}\text { (8) Proportion With } \\
\text { Satisfactory Quality }\end{array}$ \\
\hline Borehole & $1348[0.29]$ & 18 & 29 & 0.44 & 0.47 & 0.84 & 0.37 & 0.85 \\
\hline Building & $806[0.17]$ & 32 & 120 & 0.37 & 0.50 & 0.79 & 0.34 & 0.81 \\
\hline Electrification & $751[0.16]$ & 2 & 93 & 0.14 & 0.56 & 0.65 & 0.25 & 0.87 \\
\hline Dam & $624[0.13]$ & 14 & 18 & 0.79 & 0.15 & 0.74 & 0.10 & 0.50 \\
\hline Procurement & $345[0.07]$ & 41 & 87 & 0.30 & 0.58 & 0.83 & 0.47 & 0.85 \\
\hline Road & $217[0.05]$ & 4 & 167 & 0.12 & 0.52 & 0.59 & 0.22 & 0.79 \\
\hline Training & $189[0.04]$ & 26 & 80 & 0.20 & 0.60 & 0.74 & 0.42 & 0.84 \\
\hline Financial project & $157[0.03]$ & 8 & 17 & 0.38 & 0.49 & 0.79 & 0.35 & 0.84 \\
\hline Research & $122[0.03]$ & 21 & 67 & 0.11 & 0.63 & 0.72 & 0.52 & 0.99 \\
\hline Advocacy & $86[0.02]$ & 23 & 49 & 0.24 & 0.61 & 0.80 & 0.47 & 0.94 \\
\hline Canal & $76[0.02]$ & 12 & 347 & 0.70 & 0.14 & 0.45 & 0.05 & 0.92 \\
\hline
\end{tabular}
Notes: The "project type" classification refers to the primary classification for each project. Other project classifications exist. The median budget allocation in Column 3 is in thousands of US Dollars (assuming an exchange rate of US\$1: Naira 150). The sample of
projects covers those which have a positive budget allocation and for which the proportion completed evaluation variable and management scores are available. The project quality variable in Column 8 is not available for all projects. Standard deviations are in

Table 2: Descriptive Evidence on Largest Civil Service Implementing Organizations

\begin{tabular}{lccccccc} 
Civil Service Organization & $\begin{array}{c}\text { (1) Number of } \\
\text { Projects }\end{array}$ & $\begin{array}{c}\text { (2) Number of } \\
\text { Unique Project } \\
\text { Types }\end{array}$ & $\begin{array}{c}\text { (3) Budget } \\
\text { Allocation } \\
\text { (US\$mn) }\end{array}$ & $\begin{array}{c}\text { (4) Proportion } \\
\text { Never Started }\end{array}$ & $\begin{array}{c}\text { (5) Average } \\
\text { Completion } \\
\text { Rate }\end{array}$ & $\begin{array}{c}\text { (6) Proportion } \\
\text { Completed } \\
\text { Conditional on } \\
\text { Being Started }\end{array}$ & $\begin{array}{c}\text { (7) Proportion } \\
\text { Fully } \\
\text { Completed }\end{array}$ \\
\hline $\begin{array}{l}\text { Federal Ministry of Agriculture and } \\
\text { Rural Development }\end{array}$ & 797 & 9 & 144 & 0.54 & 0.29 & 0.63 \\
Satisfactory Quality
\end{tabular}

Notes: The sample covers the ten largest civil service organizations ranked by number of projects from our overall sample of projects. The "project type" classification refers to the primary classification for each project. Other project classifications exist. The budget allocation in Column 3 is in millions of US Dollars (assuming an exchange rate of US\$1: Naira 150). The sample of projects covers those which have a positive budget allocation and for which the proportion completed evaluation variable and management score 
Table 3: Origins of Management Practices

Dependent Variable: System of Equations in Autonomy and Incentives/Monitoring Management

Scores

SUR Model Estimated by Maximum Likelihood

Robust Standard Errors

CS-Autonomy

CS-Incentives/Monitoring

Characteristics of Senior Management

Average years of schooling

$0.28^{* * *}$

0.10

Average years in the organization

$(0.10)$

(0.18)

0.01

0.01

Characteristics of Other Bureaucrats

Average years of schooling

0.12

$0.28^{* *}$

Average years in the organization

0.00

0.01

$(0.01)$

Average Project Completion Rate

$-0.01$

$-0.19$

(0.10)

Decentralized Organization [yes $=1$ ]

0.09

$-0.23$

(0.08)

(0.14)

Average Project Budget

0.00

0.00

(0.00)

$(0.00)$

Average Project Complexity

0.00

$-0.01^{\star}$

(0.01)

(0.01)

Standard Deviation of Project Complexity

0.00

0.01

(0.01)

(0.01)

Correlation of residuals in SURE system

Observations

63

Notes: ${ }^{* * *}$ denotes significance at $1 \%,{ }^{* *}$ at $5 \%$, and ${ }^{*}$ at $10 \%$ level. Characteristics of management controls include the proportion of managers at an organization who are male, the average level of seniority amongst management, the average years of schooling amongst managers, their average years of service, and their average years at the organization. Characteristics of non-managerial staff controls include the proportion of nonmanagement staff at an organization who are male, the average level of seniority amongst non-management, the average years of schooling amongst non-managers, their average years of service, and their average years at the organization. We follow the grading system of the Federal Government by defining senior bureaucrats as those on grade level 12 and above. Robust standard errors are in parentheses. Columns report maximum likelihood estimates to fit a SUR model for the two dimensions of management practice. 
Table 4: Management Practices and Public Sector Service Delivery

Standard Errors: Clustered by Project Type Within Organization

\title{
OLS Estimates
}

\author{
(1) Unconditional
}

(2) Organization

(3) Project

(4) Project Type

$\begin{array}{ll}\text { (5) Binary project } \quad \text { (6) Quality-Adjusted } & \end{array}$ Controls Controls

Fixed Effects initiation Completion Rate

\begin{tabular}{|c|c|c|c|c|c|c|}
\hline \multirow[t]{2}{*}{ CS-Autonomy } & $0.11^{\star \star}$ & $0.18^{\star * *}$ & $0.17^{\star \star \star}$ & $0.18^{* * *}$ & $0.15^{\star \star \star}$ & $0.11^{* *}$ \\
\hline & $(0.05)$ & $(0.03)$ & $(0.03)$ & $(0.03)$ & $(0.03)$ & $(0.04)$ \\
\hline \multirow[t]{2}{*}{ CS-Incentives/Monitoring } & $-0.06^{*}$ & $-0.11^{\star \star *}$ & $-0.11^{\star * *}$ & $-0.14^{\star \star \star}$ & $-0.16^{\star * \star}$ & $-0.08^{\star * *}$ \\
\hline & $(0.03)$ & $(0.02)$ & $(0.02)$ & $(0.02)$ & $(0.02)$ & $(0.02)$ \\
\hline \multirow[t]{2}{*}{ CS-Other } & $0.10^{* * *}$ & 0.05 & 0.05 & $0.08^{* * *}$ & $0.06^{* *}$ & $0.08^{* * *}$ \\
\hline & $(0.04)$ & $(0.03)$ & $(0.03)$ & $(0.02)$ & $(0.03)$ & $(0.02)$ \\
\hline Organization Controls (capital, general, noise) & No & Yes & Yes & Yes & Yes & Yes \\
\hline Project Controls & No & No & Yes & Yes & Yes & Yes \\
\hline Fixed Effects & None & None & None & Project Type & Project Type & Project Type \\
\hline Adjusted R-squared & 0.07 & 0.29 & 0.29 & 0.32 & 0.36 & 0.17 \\
\hline Observations (clusters) & $4721(201)$ & $4721(201)$ & $4721(201)$ & $4721(201)$ & $4721(201)$ & $2206(144)$ \\
\hline
\end{tabular}

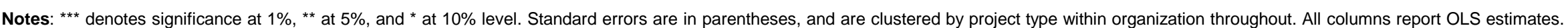
The dependent variable in Columns 1 to 4 and 6 is the proportion of the project completed (that is a continuous measure between zero and one). The dependent variable in Column 5 is a binary measure of project initiation which takes the value 1 if the project is at least $1 \%$ complete, and 0 otherwise. The dependent variable in Column 6 is the product of the proportion completed variable and the dummy variable for quality. The sample of projects in Column 6 is limited to those for which project completion and quality data is available. Project Type fixed effects relate to whether the primary classification of the project is as a financial, training, advocacy, procurement, research, electrification, borehole, dam, building, canal or road project. Project controls comprise project-level controls for the project budget, whether the project is new or a rehabilitation, and an assessment of its aggregate complexity by Nigerian engineers. Capital controls comprise organization-level controls for the logs of number of employees, total budget, and capital budget. General controls comprise organization-level controls for the share of the workforce with degrees, and the share of the workforce with postgraduate qualifications. Noise

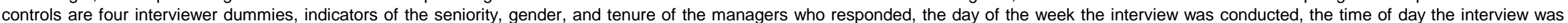
conducted, a dummy variable indicating whether the interview was conducted during Ramadan, the duration of the interview, and an indicator of the reliability of the information as coded by the interviewer. Note that no quality information is available for organizations surveyed on a Saturday, and thus the dummy variable indicating a survey took place on a Saturday is omitted in Column 6 . Total and capital budget figures are an average of organization budget figures for the years 2006-10. Figures are rounded to two decimal places. 


\title{
Table 5: Endogenous Management Practices
}

\author{
Dependent Variable: Project Completion Rate \\ Standard Errors: Clustered by Project Type Within Organization \\ Interactions in Deviation from Mean \\ OLS Estimates
}
$\begin{array}{ll}\text { (1) Capital to Total (2) Variance of Ambiguity in } & \end{array}$ Budget Ratio Portfolio of Projects

$\begin{array}{lc}\text { CS-Autonomy } & 0.17^{\star \star \star} \\ \text { CS-Incentives/Monitoring } & (0.04) \\ & -0.17^{\star \star \star} \\ \text { CS-Other } & (0.04) \\ & 0.07^{\star \star *} \\ \text { CS-Autonomy x Capital to Total Budget Ratio } & (0.02) \\ & 0.07 \\ \text { CS-Incentives/Monitoring x Capital to Total Budget Ratio } & (0.10) \\ & 0.10 \\ & (0.12)\end{array}$

CS-Autonomy x Var (Project Ambiguity)

CS-Incentives/Monitoring x Var (Project Ambiguity)

Capital to Total Budget Ratio

0.70

$(0.54)$

Var (Project Ambiguity)

$(0.03)$

\begin{tabular}{lcc}
\hline Organization Controls (capital, general, noise) & Yes & Yes \\
Project Controls & Yes & Yes \\
Fixed Effects & Project Type & Project Type \\
Adjusted R-squared & 0.33 & 0.32 \\
Observations & $4721(201)$ & $4721(201)$ \\
\hline
\end{tabular}

Notes: ${ }^{* \star *}$ denotes significance at $1 \%,{ }^{* *}$ at $5 \%$, and ${ }^{*}$ at $10 \%$ level. Standard errors are in parentheses, and are clustered by project type within organization throughout. All columns report OLS estimates. The dependent variable is the proportion of the project completed (that is a continuous measure between zero and one). Project Type fixed effects relate to whether the primary classification of the project is as a financial, training, advocacy, procurement, research, electrification, borehole, dam, building, canal or road project. Project controls comprise project-level controls for the project budget, whether the project is new or a rehabilitation, and an assessment of its aggregate complexity by Nigerian engineers. Capital controls comprise organization-level controls for the logs of number of employees, total budget, and capital budget. General controls comprise organization-level controls for the share of the workforce with degrees, the share of the workforce with postgraduate qualifications, and the span of control at the organization. Noise controls are four interviewer dummies, indicators of the seniority, gender, and tenure of the managers who responded, the day of the week the interview was conducted, the time of day the interview was conducted, a dummy variable indicating whether the interview was conducted during Ramadan, the duration of the interview, and an indicator of the reliability of the information as coded by the interviewer. Total and capital budget figures are an average of organization budget figures for the years 200610. The capital to total budget Ratio is a variable that divides an organization's capital budget by its total budget. Figures are rounded to two decimal places. 


\section{Table 6: Heterogeneous Impacts of Management Practices Related to Incentives and Monitoring}

Dependent Variable: Project Completion Rate

Standard Errors: Clustered by Project Type Within Organization

Interactions in Deviation from Mean

OLS Estimates

\begin{tabular}{llll} 
(1) Project Complexity & (2) Facilities & (3) Tenure & $\begin{array}{c}\text { (4) Intrinsic } \\
\text { Motivation }\end{array}$ \\
\hline
\end{tabular}

\begin{tabular}{|c|c|c|c|c|c|}
\hline CS-Autonomy & $\begin{array}{c}0.19^{\star \star *} \\
(0.03)\end{array}$ & $\begin{array}{c}0.20^{\star \star \star} \\
(0.03)\end{array}$ & $\begin{array}{c}0.20^{* * *} \\
(0.03)\end{array}$ & $\begin{array}{c}0.21^{\star * *} \\
(0.03)\end{array}$ & $\begin{array}{c}0.17^{\star \star \star} \\
(0.03)\end{array}$ \\
\hline CS-Incentives/Monitoring & $\begin{array}{c}-0.16^{* * *} \\
(0.03)\end{array}$ & $\begin{array}{c}-0.14^{\star * *} \\
(0.02)\end{array}$ & $\begin{array}{c}-0.11^{* * *} \\
(0.03)\end{array}$ & $\begin{array}{c}-0.17^{\star \star \star} \\
(0.03)\end{array}$ & $\begin{array}{c}-0.16^{\star \star \star} \\
(0.03)\end{array}$ \\
\hline CS-Other & $\begin{array}{c}0.08^{\star \star \star} \\
(0.02)\end{array}$ & & $\begin{array}{l}0.06^{\star *} \\
(0.03)\end{array}$ & $\begin{array}{c}0.07^{\star \star \star} \\
(0.02)\end{array}$ & $\begin{array}{c}0.08^{\star \star \star} \\
(0.03)\end{array}$ \\
\hline
\end{tabular}

CS-Incentives/Monitoring x Project Complexity

$-0.19^{* * *}$

$(0.06)$

CS-Incentives/Monitoring x CS-Facilities

$0.03^{*}$

$(0.02)$

$0.09^{\star \star \star}$

$(0.03)$

0.01

CS-Facilities

CS-Incentives/Monitoring x Average Tenure of Bureaucrats

CS-Incentives/Monitoring x Proportion of Bureaucrats Intrinsically Motivated

$(0.004)$

$0.54^{* *}$

CS-Autonomy x Proportion of Projects that Bureaucrats Report Observing Corrupt Practices On

Project Complexity

$-0.01$

Average Tenure of Bureaucrats

$-0.01$

$(0.01)$

Proportion of Bureaucrats Intrinsically Motivated

$-0.47$

$(0.33)$

Proportion of Projects that Bureaucrats Report Observing Corrupt Practices On

$-1.01^{* * *}$

(0.37)

Organization Controls (capital, general, noise)
Project Controls
Fixed Effects
Adjusted R-squared
Observations (clusters)

Organization Controls (capital, general, noise)

Project Controls

Adjusted R-squared

Yes
Yes
roject Type
0.33
$4721(201)$

Yes

$\begin{array}{ccc}\text { Yes } & \text { Yes } & \text { Yes } \\ \text { Yes } & \text { Yes } & \text { Yes } \\ \text { Project Type } & \text { Project Type } & \text { Project Type } \\ 0.32 & 0.33 & 0.33 \\ 4721(201) & 4721(201) & 4721(201)\end{array}$

\begin{tabular}{c}
\hline Yes \\
Yes \\
Project Type \\
0.33 \\
$4721(201)$ \\
\hline
\end{tabular}

Notes: ${ }^{* * *}$ denotes significance at $1 \%,{ }^{* *}$ at $5 \%$, and ${ }^{*}$ at $10 \%$ level. Standard errors are in parentheses, and are clustered by project type within organization throughout. Al columns report OLS estimates. The dependent variable is the proportion of the project completed (that is a continuous measure between zero and one). Project Type fixed effects relate to whether the primary classification of the project is as a financial, training, advocacy, procurement, research, electrification, borehole, dam, building, canal or road project. Project controls comprise project-level controls for the project budget, whether the project is new or a rehabilitation, and an assessment of its aggregate complexity by Nigerian engineers. Capital controls comprise organization-level controls for the logs of number of employees, total budget, and capital budget. General controls comprise organization-level controls for the share of the workforce with degrees, and the share of the workforce with postgraduate qualifications. Noise controls are four interviewer dummies, indicators of the seniority, gender, and tenure of the managers who responded, the day of the week the interview was conducted, the time of day the interview was conducted, a dummy variable indicating whether the interview was conducted during Ramadan, the duration of the interview, and an indicator of the reliability of the information as coded by the interviewer. Total and capital budget figures are an average of organization budget figures for the years 2006-10. In Column 1, the aggregate complexity is a project-level subjective assessment by Nigerian engineers of the relative difficulty of the project within the population of OPEN projects. In Column 3 , tenure is an organizationlevel average for the number of years officials have worked at the implementing organization. In Column 4, intrinsic motivation is an organization-level proportion of employees at an organization that answered 'The chance to serve Nigeria' to the question 'What most influenced you to take up a career in the service?' in the Civil Servants Survey. In Column 5 , observation of corrupt practices is an organization-level average of the proportion of projects officials at an organization stated on which 'I observed others breaking the service rules for their own benefit' in the Civil Servants Survey. Figures are rounded to two decimal places. 
Table 7: Bureaucrat's Engagement with Politicians and Management Practices

Robust Standard Errors

OLS Estimates

Engagement with National
Parliamentary Politicians

$\begin{array}{ll}\text { (1a) Managers } & \text { (1b) Non }\end{array}$

Managers
Engagement with State

Parliamentary Politicians

(2a) Managers (2b) Non
Engagement with Local Government Chairmen

(3a) Managers (3b) Non
Engagement with Community/Religious Groups

(4a) Managers

(4b) Non

Managers

\begin{tabular}{|c|c|c|c|c|c|c|c|c|}
\hline CS-Autonomy & $\begin{array}{c}0.19 \\
(1.05)\end{array}$ & $\begin{array}{c}0.34 \\
(0.89)\end{array}$ & $\begin{array}{c}0.04 \\
(0.68)\end{array}$ & $\begin{array}{c}0.52 \\
(0.76)\end{array}$ & $\begin{array}{l}1.98^{*} \\
(1.10)\end{array}$ & $\begin{array}{c}1.49 \\
(0.96)\end{array}$ & $\begin{array}{c}1.08 \\
(1.36)\end{array}$ & $\begin{array}{r}-0.35 \\
(1.17)\end{array}$ \\
\hline CS-Incentives/Monitoring & $\begin{array}{l}3.49^{\star \star} \\
(1.39)\end{array}$ & $\begin{array}{c}-2.46^{* \star} \\
(1.19)\end{array}$ & $\begin{array}{c}3.61^{* \star *} \\
(1.06)\end{array}$ & $\begin{array}{l}-0.43 \\
(0.89)\end{array}$ & $\begin{array}{c}3.79^{* \star \star} \\
(1.44)\end{array}$ & $\begin{array}{l}-0.32 \\
(1.30)\end{array}$ & $\begin{array}{l}3.68^{* *} \\
(1.67)\end{array}$ & $\begin{array}{l}-1.67 \\
(1.53)\end{array}$ \\
\hline CS-Other & $\begin{array}{c}1.03 \\
(1.09)\end{array}$ & $\begin{array}{c}1.06 \\
(0.95)\end{array}$ & $\begin{array}{l}-0.17 \\
(0.73)\end{array}$ & $\begin{array}{c}0.34 \\
(0.88)\end{array}$ & $\begin{array}{c}0.19 \\
(1.20)\end{array}$ & $\begin{array}{c}1.14 \\
(1.22)\end{array}$ & $\begin{array}{c}0.79 \\
(1.51)\end{array}$ & $\begin{array}{l}2.84^{* *} \\
(1.41)\end{array}$ \\
\hline Organization Controls & Yes & Yes & Yes & Yes & Yes & Yes & Yes & Yes \\
\hline Bureaucrat Controls & Yes & Yes & Yes & Yes & Yes & Yes & Yes & Yes \\
\hline Fixed Effects (bureaucrat grade) & Yes & Yes & Yes & Yes & Yes & Yes & Yes & Yes \\
\hline Adjusted R-squared & 0.08 & 0.04 & 0.02 & 0.02 & 0.07 & 0.06 & 0.06 & 0.06 \\
\hline Observations & 1175 & 1184 & 1130 & 1122 & 1140 & 1131 & 1192 & 1202 \\
\hline
\end{tabular}

Notes: ${ }^{* \star *}$ denotes significance at $1 \%,{ }^{* \star}$ at $5 \%$, and ${ }^{*}$ at $10 \%$ level. Robust standard errors are in parentheses. All columns report OLS estimates. The dependent variable in Columns 1 a and $1 \mathrm{~b}$ is the proportion of projects a bureaucrat personally engages with a national parliamentary politician on. The dependent variable in Columns $2 a$ and $2 b$ is the proportion of projects a bureaucrat personally engages with a state parliamentary politician on. The dependent variable in Columns $3 \mathrm{a}$ and $3 \mathrm{~b}$ is the proportion of projects a bureaucrat personally engages with a local government chairman on. The dependent variable in Columns $4 \mathrm{a}$ and $4 \mathrm{~b}$ is the proportion of projects a bureaucrat personally engages with a community or religious group on. Managers are those at or above grade 12. Bureaucratic tier fixed effects relate to the grade of a bureaucrat, reflecting the seniority of that bureaucrat in the civil service. Capital controls comprise organization-level controls for the logs of number of employees, total budget, and capital budget. General controls comprise organization-level controls for the share of the workforce with degrees, and the share of the workforce with postgraduate qualifications. Noise controls are four interviewer dummies, indicators of the seniority, gender, and tenure of the managers who responded, the day of the week the interview was conducted, the time of day the interview was conducted, a dummy variable indicating whether the interview was conducted during Ramadan, the duration of the interview, and an indicator of the reliability of the information as coded by the interviewer. Total and capital budget figures are an average of organization budget figures for the years 2006-10. Figures are rounded to two decimal places.
Figure 1: Project Ambiguity and the Response to CS-Incentive/Monitoring Management Practices

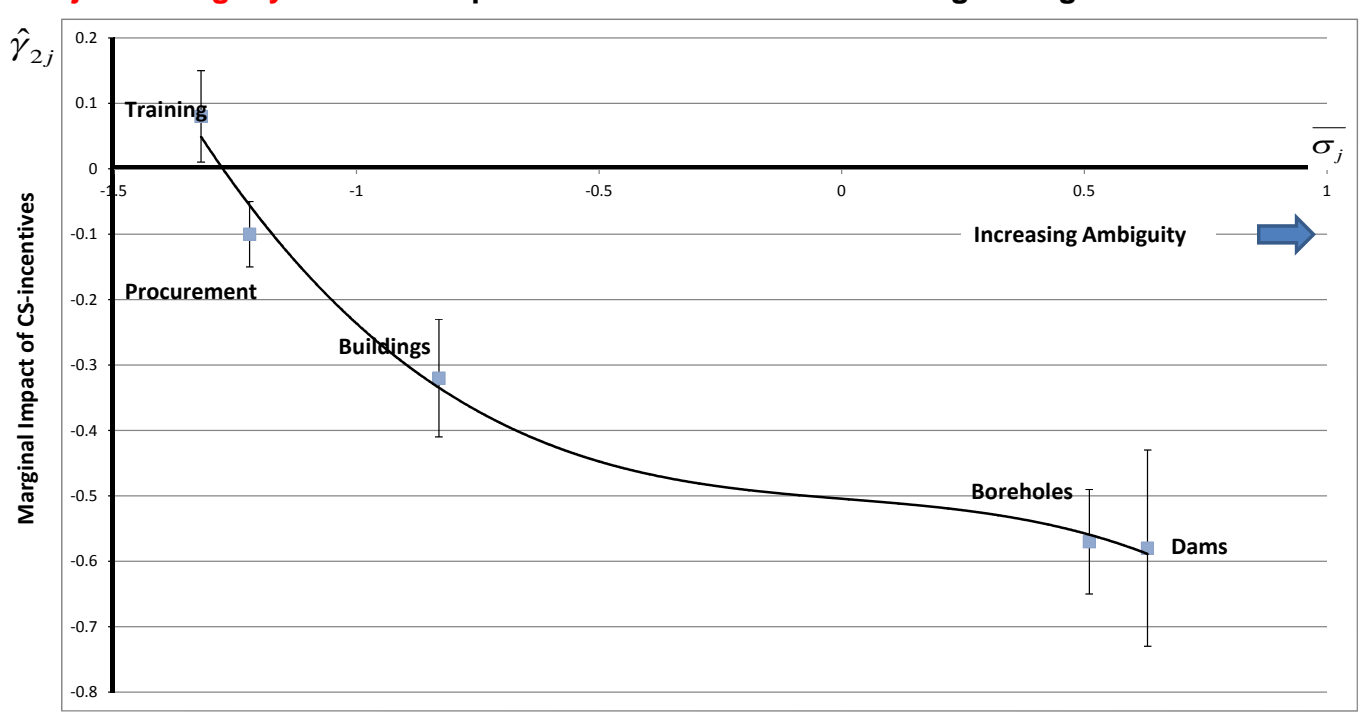

Notes: The horizontal axis measures the ambiguity of projects of a given type. We measure this design ambiguity using subcomponents of the complexity indicator described in Table A3. In particular we construct a z-score based on the design uncertainty, implementation uncertainty, design ambiguity and implementation ambiguity components of the project complexity metric. We then take the average of this over all projects of type j, denoting the average ambiguity of projects of type $\mathrm{j}$ by $\sigma \mathrm{j}$. We then estimate a specification analogous to our baseline regression model for a given project type $\mathrm{j}$ (excluding project fixed effects). We do so for five project types: boreholes, buildings, dams, procurement and training. For each project type $\mathrm{j}$ we then obtain an estimate of the partial correlation between CS-incentives and project completion rates, $\mathrm{Y} 2 \mathrm{j}$, conditional on CS-autonomy. Figure 1 then plots the five (Y2j,0j) pairs, as well as a cubic best fit. 
Table A1: Federal Civil Service Organizations Under Study

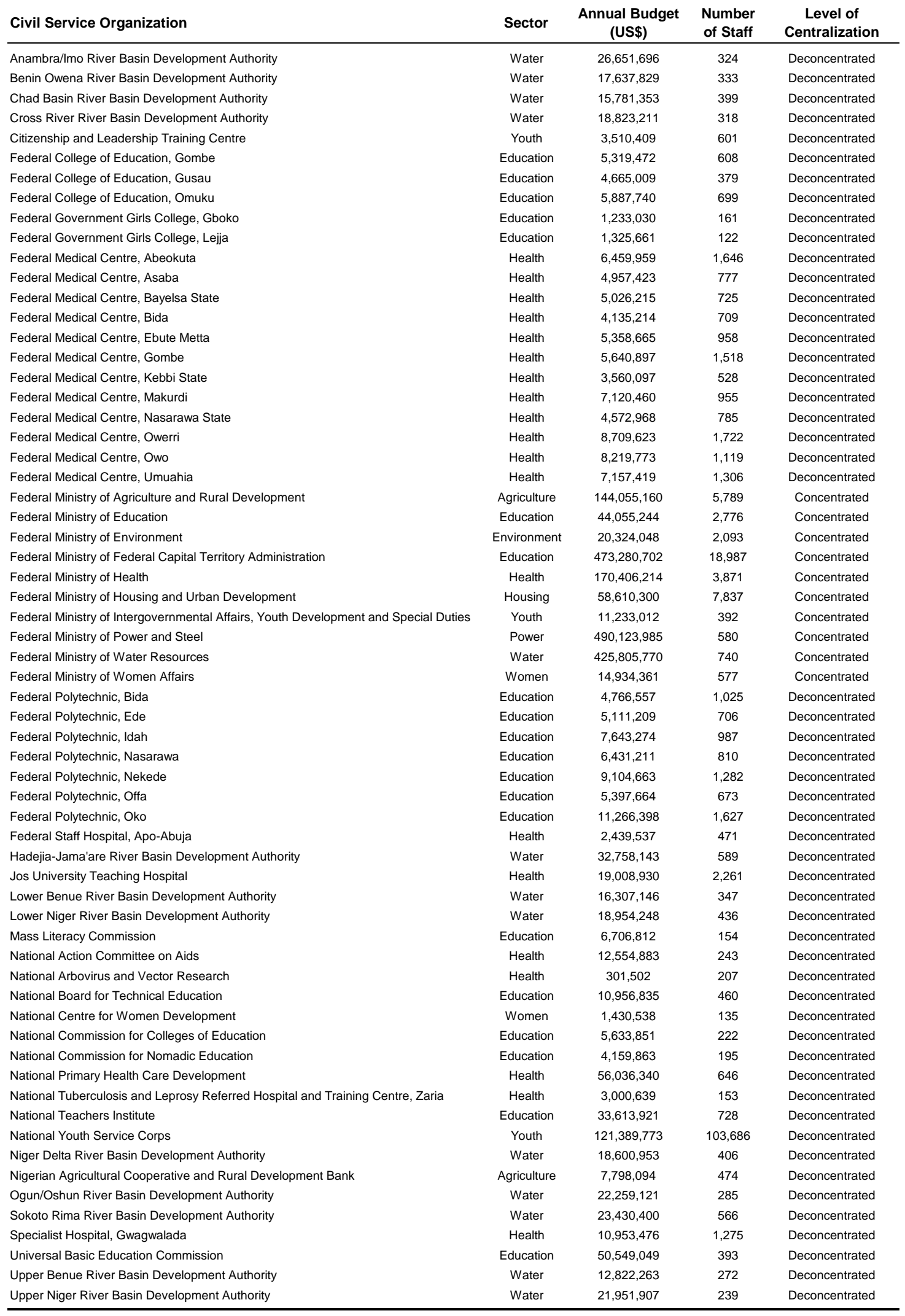

Notes: The budget figures are averages for 2006 to 2010. They are in US Dollars exchanged at a rate of US $\$ 1$ : Naira 150. Staff numbers come from administrative data for 2010. In the few cases we do not have the staff numbers explicitly, we estimate them from the personnel expenditures, which have are correlated with staff numbers with a coefficient of over 0.9. Concentrated organizations refer to the central organizing authority for the sector, with a direct line of responsibility to the President and the National Assembly. Deconcentrated organizations refer to those whose day-to-day running is largely independent of the central authority. They have boards of governors that make decisions over policy and operation and a separate budget line to the central ministries. 


\section{Table A2: Representativeness of OPEN Projects Data}

\section{(1) Federal Social Sector Budget Shares} (2) OPEN Expenditure
Shares (all projects)
(3) OPEN Expenditure Shares (sample projects)

\begin{tabular}{llll}
\hline Health & 0.21 & 0.22 & 0.19 \\
Education & 0.32 & 0.21 & 0.23 \\
Water & 0.18 & 0.19 & 0.22 \\
Power & 0.16 & 0.17 & 0.12 \\
Agriculture & 0.06 & 0.15 & 0.17 \\
Women & 0.00 & 0.01 & 0.02 \\
Youth & 0.04 & 0.01 & 0.02 \\
Environment & 0.01 & 0.01 & 0.01 \\
Housing & 0.02 & 0.02 & 0.01 \\
TOTAL & 1.00 & 1.00 & 1.00 \\
\hline
\end{tabular}

Notes: All figures are for the sum of sector budgets in 2006 and 2007. The budget figures relating to OPEN data are summations of capital warrant appropriations modified with project document figures where available rather than budget figures. The other figures are summations of the relevant appropriation-bill backed budgets. Total budget figures relate to the Executive vote only and therefore do not represent total government expenditures. They exclude expenditures by the Ministry of the Federal Capital Territory and the National Poverty Eradication Program in these sectors. 'Social sector organizations' are those that are focused on the provision of social goods and services. 'Social capital budget' refers to the capital budgets of social sector organizations. OPEN projects cover all of the social sectors in Nigeria. Health expenditures are a sum of the standard expenditures under the central organizing authority for the sector and the National Action Committee on Aids, the most prominent expenditure envelope that does not fall under the Ministry of Health but rather under the Presidency. 
Table A3: Correlation of Subcomponents of the Project Complexity Indicator

\begin{tabular}{|c|c|c|c|c|c|c|c|c|c|c|c|c|c|c|c|c|c|c|}
\hline & Mean & $\begin{array}{l}\text { Standard } \\
\text { deviation }\end{array}$ & $\begin{array}{l}\frac{N}{N} \\
\frac{N}{0} \\
\frac{d}{0} \\
\frac{0}{0}\end{array}$ & 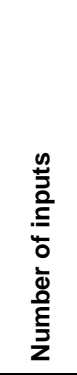 & 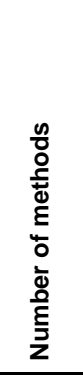 & 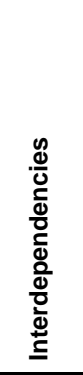 & 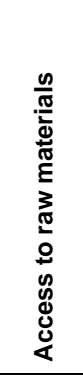 & 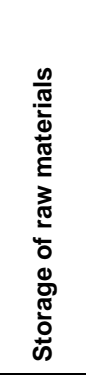 & 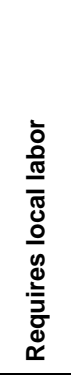 & 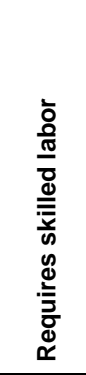 & 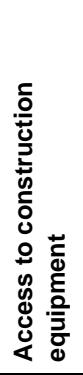 & 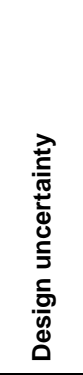 & 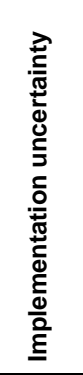 & 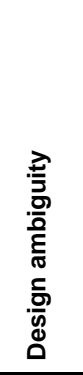 & 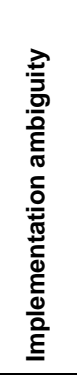 & 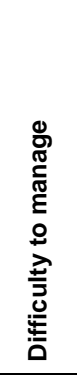 & 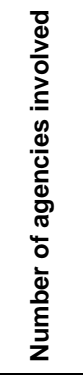 & 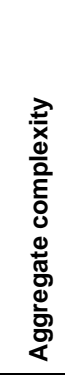 \\
\hline Project size & 0.27 & 0.45 & 1.00 & & & & & & & & & & & & & & & \\
\hline Number of inputs & 6.82 & 4.13 & 0.06 & 1.00 & & & & & & & & & & & & & & \\
\hline Number of methods & 5.04 & 2.29 & 0.33 & 0.61 & 1.00 & & & & & & & & & & & & & \\
\hline Interdependencies & 0.65 & 0.48 & -0.03 & 0.13 & 0.07 & 1.00 & & & & & & & & & & & & \\
\hline Requires skilled labor & 0.45 & 0.50 & -0.16 & -0.02 & -0.21 & 0.53 & 0.21 & -0.03 & 0.00 & 1.00 & & & & & & & & \\
\hline Access to construction equipment & 0.21 & 0.41 & -0.01 & -0.24 & 0.06 & 0.36 & 0.62 & 0.12 & 0.53 & 0.53 & 1.00 & & & & & & & \\
\hline Design uncertainty & 0.70 & 0.46 & 0.10 & 0.18 & 0.12 & 0.77 & -0.08 & 0.02 & 0.26 & 0.45 & 0.31 & 1.00 & & & & & & \\
\hline Implementation uncertainty & 0.78 & 0.41 & 0.06 & 0.26 & 0.20 & 0.58 & -0.16 & -0.01 & 0.35 & 0.42 & 0.24 & 0.78 & 1.00 & & & & & \\
\hline Design ambiguity & 0.66 & 0.47 & -0.08 & 0.08 & -0.01 & 0.84 & -0.01 & 0.08 & 0.04 & 0.60 & 0.35 & 0.73 & 0.63 & 1.00 & & & & \\
\hline Implementation ambiguity & 0.65 & 0.48 & 0.00 & 0.06 & 0.02 & 0.85 & 0.02 & 0.11 & 0.07 & 0.56 & 0.36 & 0.75 & 0.58 & 0.89 & 1.00 & & & \\
\hline Difficulty to manage & 0.28 & 0.45 & 0.15 & -0.16 & 0.24 & 0.38 & 0.47 & 0.19 & 0.64 & 0.37 & 0.81 & 0.36 & 0.27 & 0.43 & 0.43 & 1.00 & & \\
\hline Number of agencies involved & 3.54 & 0.51 & -0.01 & 0.12 & -0.05 & 0.21 & 0.11 & -0.02 & 0.25 & 0.55 & 0.21 & 0.39 & 0.54 & 0.30 & 0.26 & 0.22 & 1.00 & \\
\hline Aggregate complexity & 24.98 & 17.92 & 0.36 & 0.24 & 0.50 & 0.25 & -0.21 & 0.16 & 0.39 & -0.09 & 0.03 & 0.35 & 0.37 & 0.29 & 0.32 & 0.33 & -0.05 & 1.00 \\
\hline
\end{tabular}

Notes: The sample used is those projects in our core analysis for which we have complexity and project completion data. 'Project size' is a binary variable that aims to gauge the physical size of the project. It takes the value 1 if it is classified as equivalent to a medium scale build or larger. 'Number of inputs' counts the number of distinct product classes the finished project contains. 'Number of methods' counts the number of distinct disciplines or methods involved in implementing the project. 'Interdependencies' is a binary variable reflecting the extent of interdependencies between the activities involved in the project. It takes a value of 1 if the project is classified as highly interdependent. 'Access to raw materials' is a binary variable that takes the value 1 if raw materials could not be sourced within the state of implementation. 'Storage of raw materials' is a binary variable that takes the value 1 if some of the raw materials could not be easily stored or transported. 'Requires local labor' is a binary variable that takes the value 1 if local labor was useful or critical. 'Requires skilled labor' is a binary variable that takes the value 1 if specialized skills were necessary and difficult to obtain. 'Access to construction equipment' is a binary variable that takes the value 1 if the equipment required is difficult to obtain, heavy duty, or difficult to transport to the site. 'Design uncertainty' is a binary variable that takes on the value 1 if the design of the project is context specific. 'Implementation uncertainty 'is a binary variable that takes on the value 1 if there are substantial risks involved in implementation. 'Design ambiguity' is a binary variable that takes on the value 1 if there is a risk of redesign late on in the project. 'Implementation ambiguity' is a binary variable that takes on the value 1 if the technical risks of the project cannot be fully understood at implementation. 'Difficulty to manage' is a binary variable that takes the value 1 if the project is seen have elements that require project assessment as to the overall complexity of the project by the coding engineers. This variable is an assessment of the interaction of the other variables as well as any unassessed aspects of complexity and provides a coherent picture of the complexity of the projects by a specialist. Figures are rounded to two decimal places. 
Table A4: Defining Management Practices Using the CS Indices

\begin{tabular}{|c|c|c|c|}
\hline Management Practice & Topic & Specific Questions Related to this Topic & $\begin{array}{l}\text { Input/Output Based } \\
\text { Incentive Measure }\end{array}$ \\
\hline \multirow[t]{7}{*}{ CS-Autonomy } & Roles & $\begin{array}{l}\text { Can most staff above SGL } 7 \text { in your organization make substantive contributions to the policy formulation and } \\
\text { implementation process? }\end{array}$ & \\
\hline & & $\begin{array}{l}\text { Can most staff above SGL } 15 \text { in your organization make substantive contributions to the policy formulation and } \\
\text { implementation process? }\end{array}$ & \\
\hline & & $\begin{array}{l}\text { To what extent do the employees in this organization have the ability to determine how they carry out the } \\
\text { assignments in their daily work? }\end{array}$ & \\
\hline & Flexibility & $\begin{array}{l}\text { Does your organization make efforts to redefine its standard procedures in response to the specific needs and } \\
\text { peculiarities of a community? }\end{array}$ & \\
\hline & & $\begin{array}{l}\text { How flexible would you say your organization is in terms of responding to new practices, new techniques, and } \\
\text { regulations? }\end{array}$ & \\
\hline & & At your organization, how efficiently is best practice shared between departments? & \\
\hline & & Given past experience, how effectively would a conflict within your organization be dealt with? & \\
\hline \multirow[t]{12}{*}{ CS-Incentives/Monitoring } & Performance & Given past experience, how would under-performance be tolerated? & Input/Output \\
\hline & Incentives & Given past experience, what happens if there is a part of your organization that isn't achieving agreed results? & Output \\
\hline & & What percentage of workers were rewarded when targets were met? & Output \\
\hline & & What percentage of managers/directors were rewarded when targets were met? & Output \\
\hline & & Given past experience, are members of this organization disciplined for breaking the Public Service Rules? & Input \\
\hline & & $\begin{array}{l}\text { Given past experience, what would most likely happen to a person in this organization who accepted money or a } \\
\text { present from someone who came to them with a problem? }\end{array}$ & Input \\
\hline & Monitoring & In what kind of ways does your organization track how well it is delivering services? & Output \\
\hline & & If have performance indicators, how often are these indicators collected? & Input/Output \\
\hline & & If have performance indicators, how often are these indicators reviewed by Minister or Permanent Secretary? & Input/Output \\
\hline & & If have performance indicators, how often are these indicators reviewed by non managerial staff? & Input/Output \\
\hline & & Does the organization use performance or quality indicators for tracking the performance of its employees? & Input/Output \\
\hline & & At your organization, how highly regarded is the collection and use of data in planning and implementing projects? & Input/Output \\
\hline \multirow[t]{30}{*}{ CS-Other } & Facilities & During a typical working day ( 8 hours from $8 \mathrm{am}$ to $4 \mathrm{pm}$ ), how many hours is there electricity (PHCN or generator)? & \\
\hline & & Out of the five [5] working days, how many days is the network (GSM) coverage working for $50 \%$ of calls or more? & \\
\hline & & Out of the five [5] working days, how many hours is their internet access good enough to check e-mail? & \\
\hline & & Out of every ten [10] officers above SGL 7 , how many have access to a computer (desktop or laptop)? & \\
\hline & & $\begin{array}{l}\text { Out of every ten [10] officers above SGL } 7 \text {, how many have access to a vehicle (privately owned or otherwise) that } \\
\text { can be used for work? }\end{array}$ & \\
\hline & Skills & Out of every ten [10] officers above SGL 7 , how many can use a computer to write a memo? & \\
\hline & & Out of every ten [10] officers above SGL 7 , how many can use a computer to create a PowerPoint presentation? & \\
\hline & & Out of every ten [10] officers above SGL 7, how many can use a computer to create an Excel spreadsheet? & \\
\hline & & On which topics have trainings been performed at your organization in the last five [5] years? Technical trainings. & \\
\hline & & $\begin{array}{l}\text { On which topics have trainings been performed at your organization in the last five [5] years? Laws and } \\
\text { regulations. }\end{array}$ & \\
\hline & & $\begin{array}{l}\text { On which topics have trainings been performed at your organization in the last five [5] years? Legal rights of the } \\
\text { public. }\end{array}$ & \\
\hline & & $\begin{array}{l}\text { On which topics have trainings been performed at your organization in the last five [5] years? Good relations with } \\
\text { the public. }\end{array}$ & \\
\hline & & On which topics have trainings been performed at your organization in the last five [5] years? Ethics. & \\
\hline & & $\begin{array}{l}\text { On which topics have trainings been performed at your organization in the last five [5] years? What to do with } \\
\text { presents. }\end{array}$ & \\
\hline & & $\begin{array}{l}\text { Out of every ten [10] officers above SGL } 7 \text { at your organization, how many have had some form of training over } \\
\text { the last five [5] years? }\end{array}$ & \\
\hline & Staffing & Do you think the most senior staff of your organization talk about attracting and developing talented people? & \\
\hline & & $\begin{array}{l}\text { Do you think the most senior staff of your organization then actually goes about attracting and developing talented } \\
\text { people? }\end{array}$ & \\
\hline & & $\begin{array}{l}\text { If two people both joined your organization five years ago and one was much better at their work than the other, } \\
\text { would he/she be promoted through the service faster? }\end{array}$ & \\
\hline & & $\begin{array}{l}\text { Given past experience, if there is a 'top performing' civil servant, does your organization do their best to keep } \\
\text { him/her? }\end{array}$ & \\
\hline & & $\begin{array}{l}\text { Is the burden of achieving the organization's targets evenly distributed across its different departments, or do some } \\
\text { groups consistently shoulder a greater burden than others? }\end{array}$ & \\
\hline & & How do you feel the number of staff in your organization relates to the activities undertaken there? & \\
\hline & & What percentage of staff is doing most of the work at your organization? & \\
\hline & & $\begin{array}{l}\text { Thinking about all the projects that your organization has been involved in since your appointment here, would you } \\
\text { say that senior staff try to use the right staff for the right job? }\end{array}$ & \\
\hline & Targeting & Does your organization have a clear set of targets derived from its mission and goals? & \\
\hline & & How tough are the targets of the organization? & \\
\hline & & $\begin{array}{l}\text { When you arrive at work each day, do you and your colleagues know what your organization is trying to achieve on } \\
\text { that particular day? }\end{array}$ & \\
\hline & Culture & How effectively would you say your organization is in making the bulk of its staff feel valued? & \\
\hline & & To what extent would you say employees of your organization trust each other? & \\
\hline & & $\begin{array}{l}\text { If you think about the way that employees of this organization respond to a standard work challenge, would you } \\
\text { say that there is a set of 'shared values' amongst all the staff? }\end{array}$ & \\
\hline & & $\begin{array}{l}\text { Out of every ten [10] officers above SGL } 7 \text {, how many people from this organization participate in groups, } \\
\text { committees and activities with other people from this organization outside of the formal structure of government (for } \\
\text { example, in community or social organizations)? }\end{array}$ & \\
\hline
\end{tabular}


Table A5: Standard Errors

\section{Dependent Variable: Project Completion Rate}

\section{OLS Estimates}

$\begin{array}{llll}\text { (1) Unconditional (2) Organization } & \text { (3) Project } & \text { (4) Project Type }\end{array}$ Controls

Controls Fixed Effects

\section{CS-Autonomy}

Robust standard errors

Errors clustered by project type within organization level

Errors clustered by organization

$P$-value of clustered coefficients

Wild cluster bootstrap p-value of clustered coefficients

\begin{tabular}{|c|c|c|c|}
\hline 0.11 & 0.18 & 0.17 & 0.18 \\
\hline$(0.01)$ & $(0.01)$ & $(0.01)$ & $(0.01)$ \\
\hline$(0.05)$ & $(0.03)$ & $(0.03)$ & $(0.03)$ \\
\hline$(0.06)$ & (0.03) & $(0.03)$ & $(0.03)$ \\
\hline$[0.07]$ & [0.00] & {$[0.00]$} & {$[0.00]$} \\
\hline [0.08] & [0.02] & [0.02] & {$[0.00]$} \\
\hline-0.06 & -0.11 & -0.11 & -0.14 \\
\hline$(0.01)$ & $(0.01)$ & $(0.01)$ & $(0.01)$ \\
\hline (0.03) & (0.02) & $(0.02)$ & $(0.02)$ \\
\hline (0.03) & $(0.03)$ & $(0.03)$ & $(0.02)$ \\
\hline [0.08] & {$[0.00]$} & {$[0.00]$} & {$[0.00]$} \\
\hline [0.20] & {$[0.00]$} & {$[0.00]$} & {$[0.00]$} \\
\hline 0.10 & 0.05 & 0.05 & 0.08 \\
\hline (0.01) & $(0.02)$ & $(0.02)$ & $(0.02)$ \\
\hline$(0.04)$ & $(0.03)$ & $(0.03)$ & $(0.02)$ \\
\hline (0.03) & $(0.04)$ & $(0.03)$ & $(0.03)$ \\
\hline$[0.00]$ & {$[0.20]$} & {$[0.17]$} & {$[0.00]$} \\
\hline [0.01] & {$[0.28]$} & {$[0.26]$} & {$[0.01]$} \\
\hline No & Yes & Yes & Yes \\
\hline No & No & Yes & Yes \\
\hline None & None & None & Project Type \\
\hline 4721 & 4721 & 4721 & 4721 \\
\hline
\end{tabular}

\section{CS-Incentives/Monitoring}

Robust standard errors

Errors clustered by project type within organization level

Errors clustered by organization

$P$-value of clustered coefficients

Wild cluster bootstrap p-value of clustered coefficients

\section{CS-Other}

Robust standard errors

Errors clustered by project type within organization level

Errors clustered by organization

$P$-value of clustered coefficients

Wild cluster bootstrap p-value of clustered coefficients

Organization Controls (capital, general, noise)

\section{Project Controls}

Fixed Effects

Observations

Notes: Standard errors are in round parentheses, and are robust, clustered by project type within organization, and by organization respectively under the coefficients corresponding to a management index. Standard $p$-values and wild cluster bootstrap p-values are in square parentheses below these. All column report OLS estimates. The dependent variable is the proportion of the project completed (that is a continuous measure between zero and one). Project Type fixed effects relate to whether the primary classification of the project is as a financial, training, advocacy, procurement, research, electrification, borehole, dam, building, canal or road project. Project controls comprise project-level controls for the project budget, whether the project is new or a rehabilitation, and an assessment of its aggregate complexity by Nigerian engineers. Capital controls comprise organization-level controls for the logs of number of employees, total budget, and capital budget. General controls comprise organization-level controls for the share of the workforce with degrees, and the share of the workforce with postgraduate qualifications. Noise controls are four interviewer dummies, indicators of the seniority, gender, and tenure of the managers who responded, the day of the week the interview was conducted, the time of day the interview was conducted, a dummy variable indicating whether the interview was
conducted during Ramadan, the duration of the interview, and an indicator of the reliability of the information as coded by the interviewer. Total and capital budget figures are an average of organization budget figures for the years 2006-10. Figures are rounded to two decimal places. 
Table A6: Management Practices and Public Sector Service Delivery (boreholes only)

Standard Errors: Clustered by Organization

OLS Estimates

(1) Unconditiona

(2) Organization Controls

(3) Project
Controls

(4) Project Type Fixed Effects

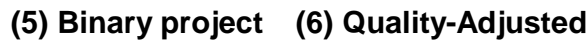
initiation Completion Rate

CS-Autonomy

$0.24^{* * *}$

$(0.08)$

$0.08^{* * *}$

$0.20^{* * *}$

$0.19^{* * *}$

$0.21^{* * *}$

$-0.10^{*}$

(0.04)

(0.04)

(0.05)

CS-Incentives/Monitoring

0.02

$-0.18^{\star * *}$

$-0.58^{\star \star *}$

$-0.88^{\star \star \star}$

$-0.82^{* * *}$

$0.36^{\star \star *}$

$(0.07)$

(0.00)

CS-Other

$-0.09$

$0.27^{* * *}$

(0.08)

(0.02)

$(0.03)$

(0.06)

$(0.11)$

$0.54^{\star \star *}$

$0.76^{\star \star \star}$

$0.63^{\star \star \star}$

$-0.15^{\star * *}$

$(0.01)$

$(0.01)$

CS-Autonomy x CS-Incentives/Monitoring

\begin{tabular}{|c|c|c|c|c|c|c|}
\hline Organization Controls (capital, general, noise) & No & Yes & Yes & Yes & Yes & Yes \\
\hline Project Controls & No & No & Yes & Yes & Yes & Yes \\
\hline Adjusted R-squared & 0.07 & 0.29 & 0.29 & 0.32 & 0.36 & 0.17 \\
\hline Observations (clusters) & $1348(18)$ & $1348(18)$ & $1348(18)$ & $1348(18)$ & $1348(18)$ & $454(14)$ \\
\hline
\end{tabular}

Notes: ${ }^{* * *}$ denotes significance at $1 \%,{ }^{* *}$ at $5 \%$, and ${ }^{*}$ at $10 \%$ level. Standard errors are in parentheses, and are clustered by organization throughout. All columns report OLS estimates. The sample is based on borehole projects only. The dependent variable in Columns 1 to 4 and 6 is the proportion of the project completed (that is a continuous measure between zero and one). The dependent variable in Column 5 is a binary measure of project initiation which takes the value 1 if the project is at least $1 \%$ complete, and 0 otherwise. The dependent variable in Column 6 is the product of the proportion completed variable and the dummy variable for quality. The sample of projects in Column 6 is limited to those for which project completion and quality data is available. Project controls comprise project-level controls

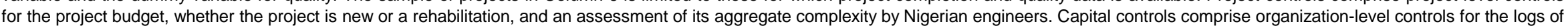
number of employees, total budget, and capital budget. General controls comprise organization-level controls for the share of the workforce with degrees, and the share of the workforce with postgraduate

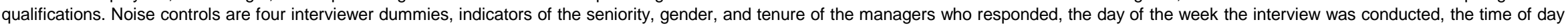
the interview was conducted, a dummy variable indicating whether the interview was conducted during Ramadan, the duration of the interview, and an indicator of the reliability of the information as coded by the interviewer. Note that no quality information is available for organizations surveyed on a Saturday, and thus the dummy variable indicating a survey took place on a Saturday is omitted in Column 6 . Total and capital budget figures are an average of organization budget figures for the years 2006-10. Figures are rounded to two decimal places. 
Table A7: Robustness Checks

Dependent Variable: Project Completion Rate

Standard Errors: Clustered by Project Type Within Organization

OLS Estimates

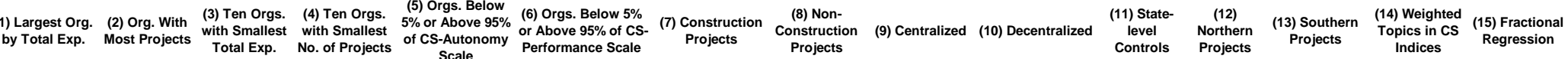

\begin{tabular}{|c|c|c|c|c|c|c|c|c|c|c|c|c|c|c|c|}
\hline \multirow[t]{2}{*}{ CS-Autonomy } & $0.17^{* * *}$ & $0.17^{* * *}$ & $0.19^{* * *}$ & $0.19^{* * *}$ & $0.23^{* * *}$ & $0.20^{* * *}$ & $0.23^{* * *}$ & $0.16^{* * *}$ & $0.17^{* * *}$ & $0.14^{* * *}$ & $0.17^{* * *}$ & $0.19^{* * *}$ & $0.22^{* * *}$ & $0.23^{* * *}$ & $1.02^{* * *}$ \\
\hline & $(0.02)$ & $(0.03)$ & $(0.03)$ & $(0.03)$ & $(0.04)$ & $(0.03)$ & $(0.05)$ & $(0.05)$ & $(0.03)$ & $(0.03)$ & $(0.03)$ & $(0.06)$ & $(0.05)$ & $(0.03)$ & $(0.17)$ \\
\hline \multirow[t]{2}{*}{ CS-Incentives/Monitoring } & $\begin{array}{c}-0.11^{* * *} \\
(0.02)\end{array}$ & $-0.13^{* * * x}$ & $-0.15^{5 * *}$ & $-0.14^{* * *}$ & $-0.24^{* * * *}$ & $-0.18^{* * * *}$ & $-0.21^{* * *}$ & $-0.06^{*}$ & $-0.24^{4 * *}$ & -0.01 & $-0.14^{* * *}$ & $-0.12^{* *}$ & $-0.30^{* * *}$ & $-0.14^{* * *}$ & $-0.96^{* * *}$ \\
\hline & $(0.02)$ & $(0.03)$ & $(0.02)$ & $(0.02)$ & $(0.04)$ & $(0.03)$ & $(0.05)$ & $(0.03)$ & $(0.04)$ & $(0.03)$ & $(0.02)$ & $(0.06)$ & $(0.10)$ & $(0.02)$ & $(0.16)$ \\
\hline cs-other & $\begin{array}{l}0.09^{* * *} \\
(0.02)\end{array}$ & $\begin{array}{l}0.05 \\
(0.03)\end{array}$ & $\begin{array}{l}0.09^{*+*} \\
(0.03)\end{array}$ & $\begin{array}{l}0.08^{* \pm *} \\
(0.03)\end{array}$ & $\begin{array}{l}0.09^{* * * *} \\
(0.03)\end{array}$ & $\begin{array}{l}0.06^{* *} \\
(0.03)\end{array}$ & $\begin{array}{l}0.11^{+*} \\
(0.05)\end{array}$ & $\begin{array}{l}0.06^{*} \\
(0.03)\end{array}$ & $\begin{array}{l}0.18^{*+* *} \\
(0.05)\end{array}$ & $\begin{array}{l}-0.03 \\
(0.04)\end{array}$ & $\begin{array}{l}0.08^{*+* *} \\
(0.03)\end{array}$ & $\begin{array}{l}-0.03 \\
(0.08)\end{array}$ & $\begin{array}{l}0.10^{*} \\
(0.05)\end{array}$ & $\begin{array}{l}0.08^{+* * *} \\
(0.02)\end{array}$ & $\begin{array}{l}0.49^{*+* *} \\
(0.15)\end{array}$ \\
\hline $\begin{array}{l}\text { Organization Controls } \\
\text { (capital, general, noise) }\end{array}$ & Yes & Yes & Yes & Yes & Yes & Yes & Yes & Yes & Yes & Yes & Yes & Yes & Yes & Yes & Yes \\
\hline Project Controls & Yes & Yes & Yes & Yes & Yes & Yes & Yes & Yes & Yes & Yes & Yes & Yes & Yes & Yes & Yes \\
\hline Fixed Effects & Project Type & Project Type & Project Type & Project Type & Project Type & Project Type & Project Type & Project Type & Project Type & Project Type & Project Type & Project Type & Project Type & Project Type & Project Type \\
\hline Adjusted R-squared & 0.24 & 0.32 & 0.31 & 0.32 & 0.31 & 0.33 & 0.33 & 0.29 & 0.36 & 0.26 & 0.28 & 0.28 & 0.21 & 0.33 & \\
\hline Observations (clusters) & $4201(197)$ & $3924(192)$ & $4601(176)$ & $4711(191)$ & $3810(145)$ & $4209(181)$ & $3822(82)$ & $899(119)$ & $2434(53)$ & $2287(148)$ & $4269(63)$ & $2049(91)$ & $1895(104)$ & $4721(201)$ & $4721(201)$ \\
\hline
\end{tabular}

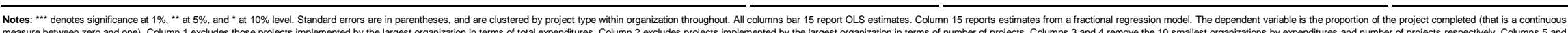
6 exclude organizations at the top and bottom of the CS-autonomy and CS-incentives/monitoring management scales respectively. Column 7 includes only construction projects (borehole, building, electrification, dam, road and canal) and Column 8 includes only non-construction projects. Column 9 restricts our specification to those projects implemented by

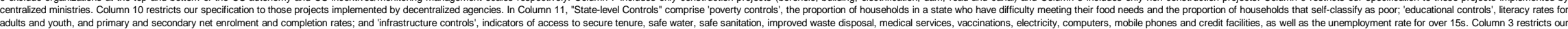

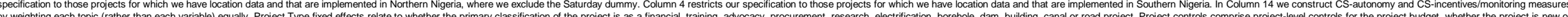

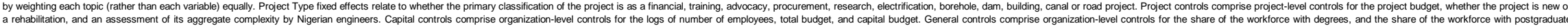

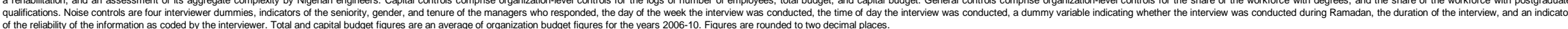


Table A8: Alternative Groupings of Management Practices

Standard Errors: Clustered by Project Type Within Organization

OLS Estimates

$\begin{array}{cccc}\begin{array}{ccc}\text { (1) Baseline } \\ \text { Definitions }\end{array} & \begin{array}{c}\text { (2) Alternative } \\ \text { Autonomy Measure }\end{array} & \begin{array}{c}\text { (3) Alternative } \\ \text { Incentives Measure }\end{array} & \begin{array}{c}\text { (4) Split } \\ \text { Incentives }\end{array}\end{array}$

\begin{tabular}{|c|c|c|c|c|}
\hline CS-Autonomy (roles, flexibility) & $\begin{array}{l}0.18^{* * *} \\
(0.03)\end{array}$ & & $\begin{array}{l}0.18^{\star * \star} \\
(0.03)\end{array}$ & $\begin{array}{l}0.39^{* \star \star} \\
(0.06)\end{array}$ \\
\hline CS-Incentives/Monitoring (incentives, monitoring) & $\begin{array}{c}-0.14^{\star * *} \\
(0.02)\end{array}$ & $\begin{array}{c}-0.12^{\star \star *} \\
(0.03)\end{array}$ & & \\
\hline CS-Other & $\begin{array}{l}0.08^{* * *} \\
(0.02)\end{array}$ & $\begin{array}{c}0.09^{* \star *} \\
(0.02)\end{array}$ & $\begin{array}{l}0.06^{* * *} \\
(0.02)\end{array}$ & $\begin{array}{l}0.09^{* \star *} \\
(0.03)\end{array}$ \\
\hline Alternative CS-Autonomy (roles, skills) & & $\begin{array}{c}0.09^{* * *} \\
(0.03)\end{array}$ & & \\
\hline $\begin{array}{l}\text { Alternative CS-Incentives/Monitoring (incentives, } \\
\text { monitoring, targeting) }\end{array}$ & & & $\begin{array}{c}-0.12^{\star * *} \\
(0.02)\end{array}$ & \\
\hline CS-Incentives (input) & & & & $\begin{array}{l}-0.04^{* *} \\
(0.02)\end{array}$ \\
\hline CS-Incentives (output) & & & & $\begin{array}{l}-0.07^{* *} \\
(0.03)\end{array}$ \\
\hline CS-Incentives (both) & & & & $\begin{array}{l}-0.08^{\star \star \star} \\
(0.02)\end{array}$ \\
\hline Organization Controls (capital, general, noise) & Yes & Yes & Yes & Yes \\
\hline Project Controls & Yes & Yes & Yes & Yes \\
\hline Fixed Effects & Project Type & Project Type & Project Type & Project Type \\
\hline Adjusted R-squared & 0.32 & 0.31 & 0.32 & 0.32 \\
\hline Observations (clusters) & $4721(201)$ & $4721(201)$ & $4721(201)$ & $4721(201)$ \\
\hline
\end{tabular}

Notes: ${ }^{* * *}$ denotes significance at $1 \%,{ }^{* *}$ at $5 \%$, and ${ }^{*}$ at $10 \%$ level. Standard errors are in parentheses, and are clustered by project type within organization throughout. All columns report OLS estimates. The dependent variable is the proportion of the project completed (that is a continuous measure between zero and one). The management practices included in the CS-other measure varies across columns depending on which practices are included in the CS-autonomy and CSincentives/monitoring measures. Project Type fixed effects relate to whether the primary classification of the project is as a financial, training, advocacy, procurement, research, electrification, borehole, dam, building, canal or road project. Project controls comprise project-level controls for the project budget, whether the project is new or a rehabilitation, and an assessment of its aggregate complexity by Nigerian engineers. Capital controls comprise organization-level controls for the logs of number of or a rehabilitation, and an assessment of its aggregate complexity by Nigerian engineers. Capital controls comprise organization-level controls for the logs of number of
employees, total budget, and capital budget. General controls comprise organization-level controls for the share of the workforce with degrees, and the share of the employees, total budget, and capital budget. General controls comprise organization-level controls for the share of the workforce with degrees, and the share of the
workforce with postgraduate qualifications. Noise controls are four interviewer dummies, indicators of the seniority, gender, and tenure of the managers who workforce with postgraduate qualifications. Noise controls are four interviewer dummies, indicators of the seniority, gender, and tenure of the managers who
responded, the day of the week the interview was conducted, the time of day the interview was conducted, a dummy variable indicating whether the interview was conducted during Ramadan, the duration of the interview, and an indicator of the reliability of the information as coded by the interviewer. Total and capital budget figures are an average of organization budget figures for the years 2006-10. Figures are rounded to two decimal places. 
Table A9: Decomposing the Impacts of Management Practices

Dependent Variable: Proportion Project Completed

Standard Errors: Clustered by Project Type Within Organization

OLS Estimates

(1) Roles (2) Flexibility (3)

(3) Performance

incentives

(4) Monitoring

(5) Culture

Targeting (7) Facilities

(8) Skills

(9) Staffing

(10) All

(11) Management

\begin{tabular}{lc}
\hline CS-Roles & $0.27^{\star \star \star}$ \\
& $(0.06)$
\end{tabular}

$0.18^{\star \star \star}$

$(0.05)$

$-0.08^{*}$

CS-Performance Incentives

$0.33^{*}$

CS-Monitoring

$0.33^{\star \star}$
$(0.04)$

$(0.04)$
$0.11^{* *}$

(0.04)

CS-Culture

(0.05)

$-0.07$

CS-Targeting

(0.04)

CS-Facilities

0.03

0.03
$(0.04)$

$0.13^{\star \star *}$

$(0.06)$

$-0.28^{\text {** }}$

$(0.06)$

0.01

(0.03)

0.07

(0.04)

$(0.05)$

CS-Skills

0.08

(0.04)

CS-Staffing

(0.07)

$0.14^{* *}$

$-0.06$

(0.06)

CS-Management

(0.06)

0.03

$(0.03)$

$\mathrm{H}_{0}$ : CS-Autonomy Components Equal [p-value]

$\mathrm{H}_{0}$ : CS-Incentives/Monitoring Components Equal [p-value]

Organization Controls (capital,

general, noise)

Project Controls

Fixed Effects

Yes Yes Yes

Yes Yes

Yes

Project Type

Project Type

Project Type Project Type

0.29

0.30

Yes

Yes Yes

Yes Yes

Yes Yes

Yes
Yes

$[0.00]$
$[0.06]$

Adjusted R-squared

$0.31 \quad 0.30$

$4721(201)$

$4721(201)$

0.29 Project Type Project Type

Type Projes

Yes

Yes

Observations (clusters) $\quad 4721(201) \quad 4721(201)$

4721 (201)

0.29

0.30

0.29

0.29

roject Type

Project Type Notes: *** denotes significance at $1 \%$, ** at $5 \%$, and * at $10 \%$ level. Standard errors are in parentheses, and are clustered by project type within organization throughout. All columns report OLS estimates. The dependent variable in all columns is the proportion of available to staff. The variable 'skills' measures the skills and training opportunities embodied in the staff body. The variable 'staffing' measures the effective utilization of that body of staff. The variable 'targeting' examines the extent of use of targets. The variable 'flexibility' measures the extent to which the organization is able to respond to best practice and project peculiarities. The variable 'roles' measures the extent to which staff can play a role in defining the direction of the organization. The variable 'culture' measures whether the organization inculcates a productive work culture. Together these components make up our autonomy variable. The variable 'monitoring' focuses on the tracking of performance of individuals and projects. The variable 'performance' examines the use of incentives both to reward success and punish fallure. Project Type fixed effects relate to whether the primary classification of the project is as a financial, training, advocacy, procurement, research, electrification, borehole, dam, building, canal or road project. Project controls comprise project-level controls for the project budget, whether the project is new or a rehabilitation, and an assessment of its aggregate complexity by Nigerian engineers. Capital controls comprise organization-level controls for the logs of number indicators of the seniority, gender, and tenure of the manars who responded, the day of the woek the interve sh was conducted, the time of day the interview was conducted, a dummy variable indicating whether the interview was conducted during Ramadnies,

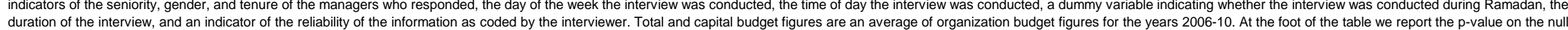
that the coefficients in Column 10 on the variables that make up the CS-autonomy measure (those associated with roles and flexibility) are of equal magnitude. We also report the p-value on the null that the coefficients in Column 10 on the variables that make up the CS-incentives/monitoring measure (those associated with performance incentives and monitoring) are of equal magnitude. Figures are rounded to two decimal places. 
Table A10: Management Practices and the Assignment of Projects to Organizations

Dependent Variable: Binary Variable Indicating Organization Implementing Project

Standard Errors: Clustered by Organization

Conditional Logit Model

$\begin{array}{llll}\text { (1) Unconstrained } & \text { (2) Feasible Pairs by (3) Feasible Pairs by (4) Organization } & \text { (5) Project }\end{array}$ Pairs

Sector

Complexity

Controls

Interaction

cS-Autonomy

0.35

$0.53^{*}$

0.37

0.40

CS-Incentives/Monitoring

$(0.22)$
-0.17

$(0.27)$

$(0.24)$

0.35

(0.26)

$-0.33$

$-0.26$

(0.29)

\section{CS-Other}

Senior Bureaucrat's Span of Control

0.57

Tenure of Senior Bureaucrats

Tenure of Low-tier Bureaucrats

Proportion of Senior Bureaucrats That Report Being Intrinsically Motivated

Proportion of Low-tier Bureaucrats That Report Being Intrinsically Motivated

Proportion of Projects that Senior Bureaucrats that Report Observing Corrupt Practices On

Proportion of Projects that Low-tier Bureaucrats that Report Observing Corrupt Practices On

\begin{tabular}{|c|c|c|c|c|c|}
\hline & & & & $(0.03)$ & $(0.04)$ \\
\hline Organization Controls (capital, general, noise) & No & No & No & Yes & Yes \\
\hline Interactions of Project and Organizational Characteristics & No & No & No & No & Yes \\
\hline Project-Organization Paired Observations (clusters) & $297423(63)$ & $44429(59)$ & $33480(59)$ & $33370(58)$ & $33370(58)$ \\
\hline
\end{tabular}

Notes: ${ }^{* \star *}$ denotes significance at $1 \%,{ }^{* *}$ at $5 \%$, and ${ }^{*}$ at $10 \%$ level. Standard errors are in parentheses, and are clustered within organization throughout. All Columns report conditional logit estimates. The data is set up as follows. For each project, we associate a binary variable with 63 values corresponding to the 63 organizations in the core analysis of the paper. This variable takes the value one if the project is implemented at that organization, and zero otherwise. Thus, for each of our 4721 projects, we have 63 'project-organization' observations. These 297,423 observations are what makes up the 'unrestricted only organization in the sector. senior bureaucrats that report observing corrupt practices, this organization drops out, leaving 33,370 project-organization pairs. In Column 5 we restrict the feasible pairs further by assuming projects can only potentially be assigned to organizations in the same sector that are observed being tasked to implement at least one project of similar or greater complexity. Capital controls comprise organization-level controls for the logs of number of employees, total budget, and capital budget. General controls comprise organization-level controls for the share of the workforce with degrees, and the share of the workforce with postgraduate qualifications. Noise controls are four interviewer dummies, indicators of the seniority, gender, and tenure of the managers who responded, the day of the week the interview was conducted, the time of day the interview was conducted, a dummy variable indicating whether the interview was conducted during Ramadan, the duration of the interview, and an indicator of the reliability of the information as coded by the interviewer. Total and capital budget figures are an average of organization budget figures for the years 2006-10. We follow the grading system of the Federal Government by defining senior bureaucrats as those on grade level 12 and above. The proportion of staff intrinsically motivated refers to the fraction of employees at an organization that answered 'The chance to serve Nigeria' to the question 'What most influenced you to take up a career in the service?' in the Civil Servants Survey. The percentage of staff who observed corruption refers to the average proportion of projects officials at an organization stated on which 'l observed others breaking the service rules for their own benefit' in the Civil Servants Survey. Figures are rounded to two decimal places. 
Table A11: Management Practices and Public Sector Service Delivery at the Organization Level

\section{Robust Standard Errors OLS Estimates}

$\begin{array}{cccc}\begin{array}{c}\text { (1) Number of } \\ \text { Projects Assigned } \\ \text { to Organization }\end{array} & \begin{array}{c}\text { (2) Number of } \\ \text { Unique Project } \\ \text { Types Assigned to } \\ \text { Organization }\end{array} & \begin{array}{c}\text { (3) Project } \\ \text { Complexity }\end{array} & \text { (4) Log Organizational } \\ \text { Budget }\end{array}$

\begin{tabular}{|c|c|c|c|c|}
\hline \multirow[t]{2}{*}{ CS-Autonomy } & 22.17 & 0.21 & 1.56 & 0.03 \\
\hline & $(19.57)$ & $(0.27)$ & $(1.89)$ & $(0.05)$ \\
\hline \multirow[t]{2}{*}{ CS-Incentives/Monitoring } & 10.07 & -0.01 & -0.47 & 0.05 \\
\hline & $(24.87)$ & $(0.40)$ & $(1.53)$ & $(0.07)$ \\
\hline \multirow[t]{2}{*}{ CS-Other } & -19.92 & -0.01 & -2.10 & 0.03 \\
\hline & $(28.30)$ & $(0.37)$ & $(1.66)$ & $(0.05)$ \\
\hline Organization Controls (capital, general, noise) & Yes & Yes & Yes & Yes \\
\hline Observations & 63 & 63 & 63 & 63 \\
\hline
\end{tabular}

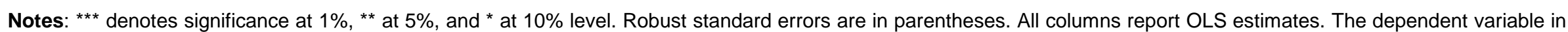

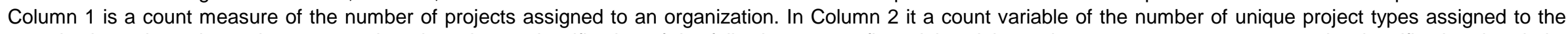

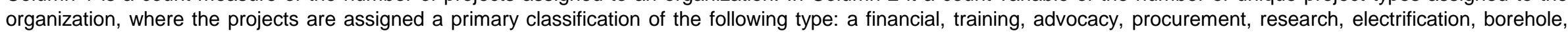

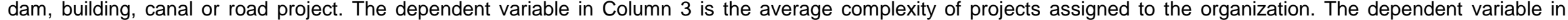

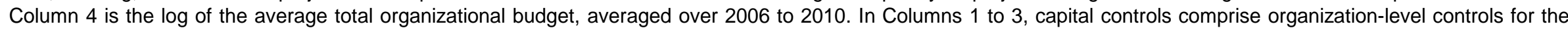

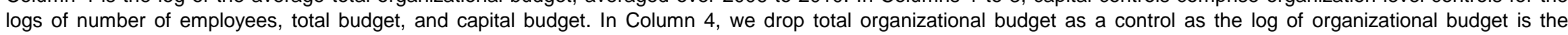

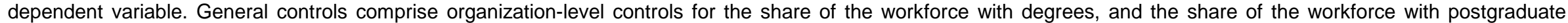

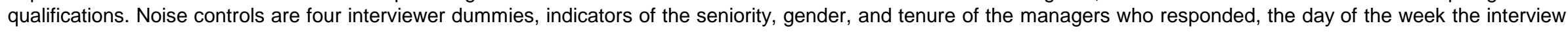

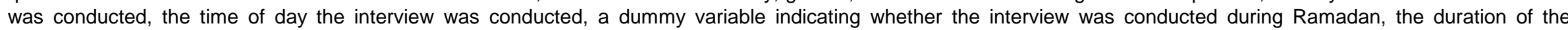

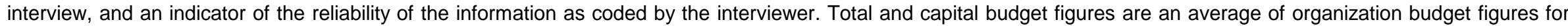
the years 2006-10. Figures are rounded to two decimal places. 
Table A12: Bureaucrat Characteristics and Management Practices

Means, standard deviations and regression coefficients

Partial Correlation Coefficients

$\begin{array}{ccc}\begin{array}{c}\text { (1) Mean } \\ \text { (s.d.) }\end{array} & \begin{array}{c}\text { (2) Coefficient on } \\ \text { CS-Autonomy }\end{array} & \begin{array}{l}\text { (3) Coefficient on CS- } \\ \text { Incentives/Monitoring }\end{array}\end{array}$

Proportion of Bureaucrats Who Knew Direct Boss Before Starting Posting $\quad 0.00$

$(0.01)$

Proportion of Bureaucrats Who Knew Managers Before Starting Posting $\quad 0.00$

$(0.01)$

Average Number of Close Colleagues Known Before Starting Posting

\begin{tabular}{lccc} 
& $(3.18)$ & $(0.41)$ & $(0.44)$ \\
Proportion of Bureaucrats Being the First Family Member to Join Service & 0.48 & 0.02 & -0.01 \\
\hline
\end{tabular}

Tenure of Senior Bureaucrats

15

$0.37+0.01)$

Tenure of Low-tier Bureaucrats

Proportion of Senior Bureaucrats Intrinsically Motivated

15

$\begin{array}{ll}0.37 & -0.08 \\ (0.66) & (0.71)\end{array}$

$-0.08$

Proportion of Low-tier Bureaucrats Intrinsically Motivated

$\begin{array}{cc}0.11 & 0.17 \\ (0.52) & (0.56)\end{array}$

0.17

$-0.01$

Proportion of Projects that Senior Bureaucrats that Report Observing Corrupt

Practices On

0.35

$(0.10)$

Proportion of Projects that Low-tier Bureaucrats that Report Observing

Corrupt Practices On

0.00

$(0.01)$

$(0.01)$

$\begin{array}{ll}-0.02 & 0.01 \\ (0.01) & (0.01)\end{array}$

$(0.11)$

$-0.01$

$(0.01)$

$(0.01) \quad(0.02)$

Notes: ${ }^{* \star *}$ denotes significance at $1 \%,{ }^{* *}$ at $5 \%$, and ${ }^{*}$ at $10 \%$ level. Columns 2 to 3 report OLS coefficients on CS-autonomy and CS-incentives/monitoring where organizational controls are included. The organizational controls use the same capital and general controls from the baseline specification: capital controls comprise organization-level controls for the logs of number of employees, total budget, and capital budget. General controls comprise organization-level controls for the share of the workforce with degrees, and the share of the workforce with postgraduate qualifications. In Column 1, standard deviations are in parentheses. In Columns 2 and 3 standard errors are in parentheses. The proportion of bureaucrats who knew their direct boss before starting their posting is an organization-level average of those bureaucrats who answered posily managers betre starting heir posting is an organization-level average of hose bureaucrats who answered postively to a question outlining possible connections to the officials' managers before of colleagues an oflial stated that they had connections with betore they came to work at he organization. Proporlion of bureaucrats being the first family member to join service is an organizalion-level average of those bureaucrats who answered 'Yes' to the question 'Are you the first member of your famlly to enter the Federal service. Tenure of bureaucrats refers to the number of years they have served in the organization for. The proportion of staff intrinsically motivated refers to the fraction of employees at an organization that answered 'The chance to serve Nigeria' to the question 'What most influenced you to take up a career in the senvice?. The percentage of staft who observed corruption refers to the average proportion or projects officials al an organization stated on wh lobsened olhers breaking the service rules for their own benefit. These practices on, we lose one organization (that implemented a single project) in which no senior bureaucrat answered the question. Figures are rounded to two decimal places. 
Figure A1: Impact of Management Practices For Different Thresholds of Project Success

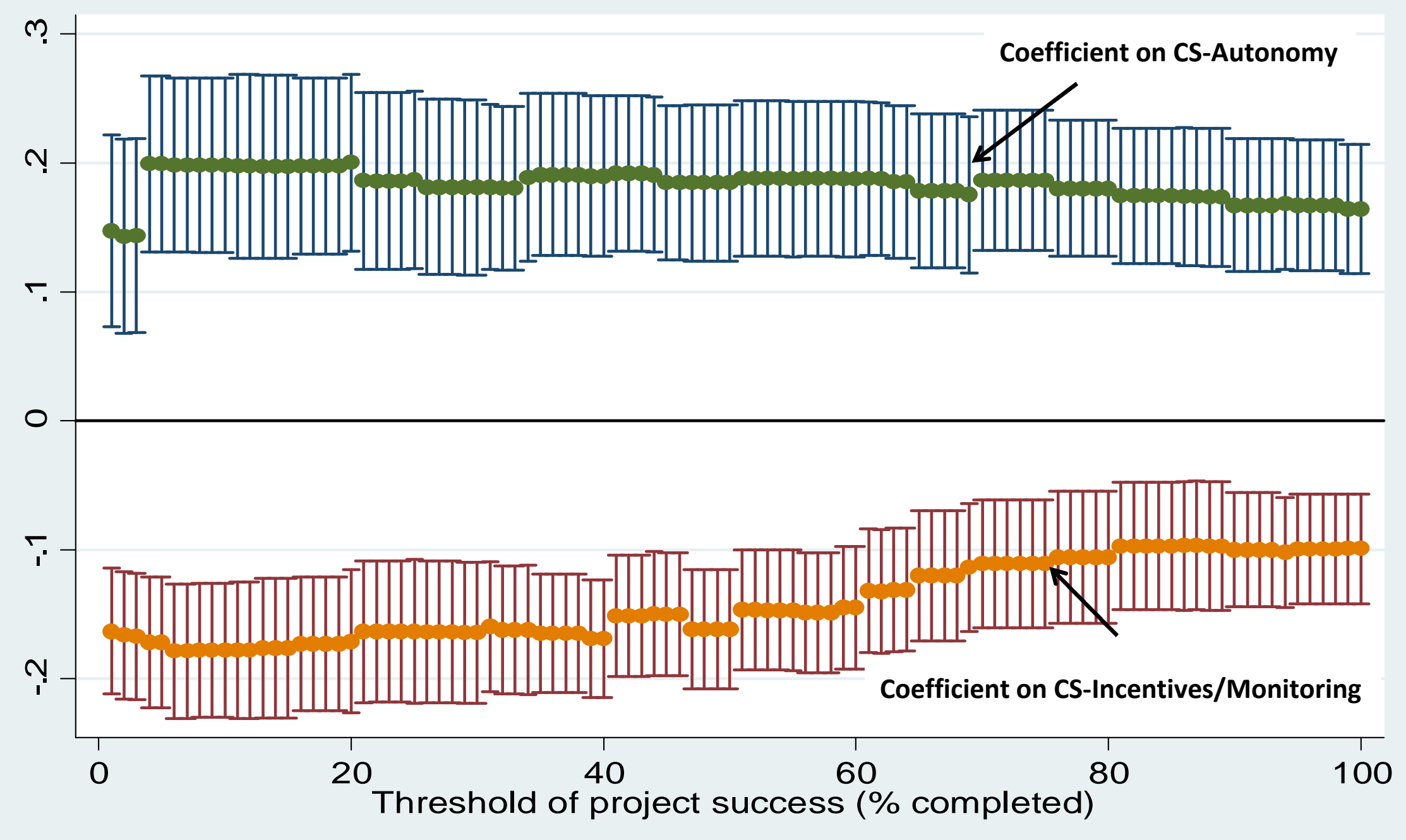

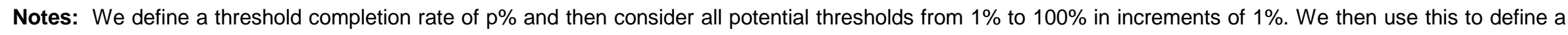

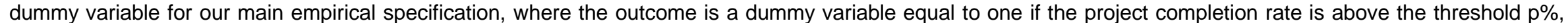

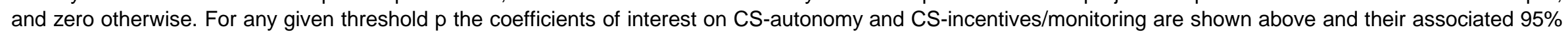
confidence interval. 